Review

\title{
Progress in ZnO Nanosensors
}

\author{
Miaoling Que ${ }^{1}$, Chong Lin ${ }^{2}{ }^{\oplus}$, Jiawei Sun ${ }^{1}$, Lixiang Chen ${ }^{1}$, Xiaohong Sun ${ }^{1}$ and Yunfei Sun ${ }^{1, *}$ \\ 1 College of Electronic and Information Engineering, Suzhou University of Science and Technology, \\ Suzhou 215009, China; quemiaoling@126.com (M.Q.); tayloree2009@163.com (J.S.); \\ chenlixiang0426@163.com (L.C.); zixuan19861002@126.com (X.S.) \\ 2 Jiangxi Province Key Laboratory of Polymer Micro/Nano Manufacturing and Devices, School of Chemistry, \\ Biology and Materials Science, East China University of Technology, Nanchang 330013, China; \\ lin_chong@ecut.edu.cn \\ * Correspondence: yfsun@usts.edu.cn
}

check for

updates

Citation: Que, M.; Lin, C.; Sun, J.; Chen, L.; Sun, X.; Sun, Y. Progress in ZnO Nanosensors. Sensors 2021, 21, 5502. https://doi.org/10.3390/ s21165502

Academic Editor: Dimitris Tsoukalas

Received: 29 June 2021

Accepted: 12 August 2021

Published: 16 August 2021

Publisher's Note: MDPI stays neutral with regard to jurisdictional claims in published maps and institutional affiliations.

Copyright: (c) 2021 by the authors. Licensee MDPI, Basel, Switzerland. This article is an open access article distributed under the terms and conditions of the Creative Commons Attribution (CC BY) license (https:// creativecommons.org/licenses/by/ $4.0 /)$.

\begin{abstract}
Developing various nanosensors with superior performance for accurate and sensitive detection of some physical signals is essential for advances in electronic systems. Zinc oxide ( $\mathrm{ZnO})$ is a unique semiconductor material with wide bandgap $(3.37 \mathrm{eV})$ and high exciton binding energy $(60 \mathrm{meV})$ at room temperature. $\mathrm{ZnO}$ nanostructures have been investigated extensively for possible use as high-performance sensors, due to their excellent optical, piezoelectric and electrochemical properties, as well as the large surface area. In this review, we primarily introduce the morphology and major synthetic methods of $\mathrm{ZnO}$ nanomaterials, with a brief discussion of the advantages and weaknesses of each method. Then, we mainly focus on the recent progress in $\mathrm{ZnO}$ nanosensors according to the functional classification, including pressure sensor, gas sensor, photoelectric sensor, biosensor and temperature sensor. We provide a comprehensive analysis of the research status and constraints for the development of $\mathrm{ZnO}$ nanosensor in each category. Finally, the challenges and future research directions of nanosensors based on $\mathrm{ZnO}$ are prospected and summarized. It is of profound significance to research $\mathrm{ZnO}$ nanosensors in depth, which will promote the development of artificial intelligence, medical and health, as well as industrial, production.
\end{abstract}

Keywords: $\mathrm{ZnO}$ nanostructure; synthetic method; pressure sensor; gas sensor; photoelectric sensor; biosensor; temperature sensor

\section{Introduction}

Sensors, as devices that can sense and convert various measured signals, have been developed and improved upon for over a decade [1]. Due to the small size, high sensitivity and high precision, nanosensors have attracted extensive attention in recent years [2,3] and they are used in numerous fields, such as healthcare, military, industrial control and robotics, networking and communications and environmental monitoring.

$\mathrm{ZnO}$, with a wide bandgap and high exciton binding energy, has long been investigated for a variety of applications, such as sensors, light-emitting diodes, solar cells and laser diodes, which can work in the wavelength ranging from ultraviolet to the visible region [4,5]. Compared with bulk materials, $\mathrm{ZnO}$ nanostructures exhibit many special properties, such as quantum size effect, high specific surface area and dimension limitation effect. Using the excellent characteristics of $\mathrm{ZnO}$ nanomaterials, various sensors, piezoelectric and photoelectric devices have been prepared [6,7], which are widely used in biotechnology, scientific research and industrial production. ZnO nanosensors have aroused extensive concern and researchers are working to achieve nanosensors with advantages such as low cost, high stability, high sensitivity, fast response and fast recovery [8,9]. Here, we provide an overview of recent progress in $\mathrm{ZnO}$ nanosensors. We concentrate on the $\mathrm{ZnO}$ nanostructures and their fabrication methods; then, we give a review of $\mathrm{ZnO}$ nanosensors by classification of their functions, respectively. 


\section{ZnO Nanostructures and Synthetic Method}

\subsection{ZnO Nanostructures}

$\mathrm{ZnO}$, as an important semiconducting material, exhibits splendid and abundant nanostructures [10]. According to the size and morphology, $\mathrm{ZnO}$ nanomaterials can be divided into four categories, including zero-dimensional nanomaterials, such as quantum dot (QD) [11] and nanoparticle (NP) [12], one-dimensional nanomaterials, such as nanowire (NW) [13], nanobelt (NB) [14], nanoneedle (NN) [15] and nanorod (NR) [16], two-dimensional nanomaterials, such as nanofilm [17] and nanosheet (NS) [18] and threedimensional nanomaterials, such as porous $\mathrm{ZnO}$ materials [19] and nanocluster [20]. Figure 1 shows the scanning electron microscope (SEM) images of some $\mathrm{ZnO}$ nanostructures.
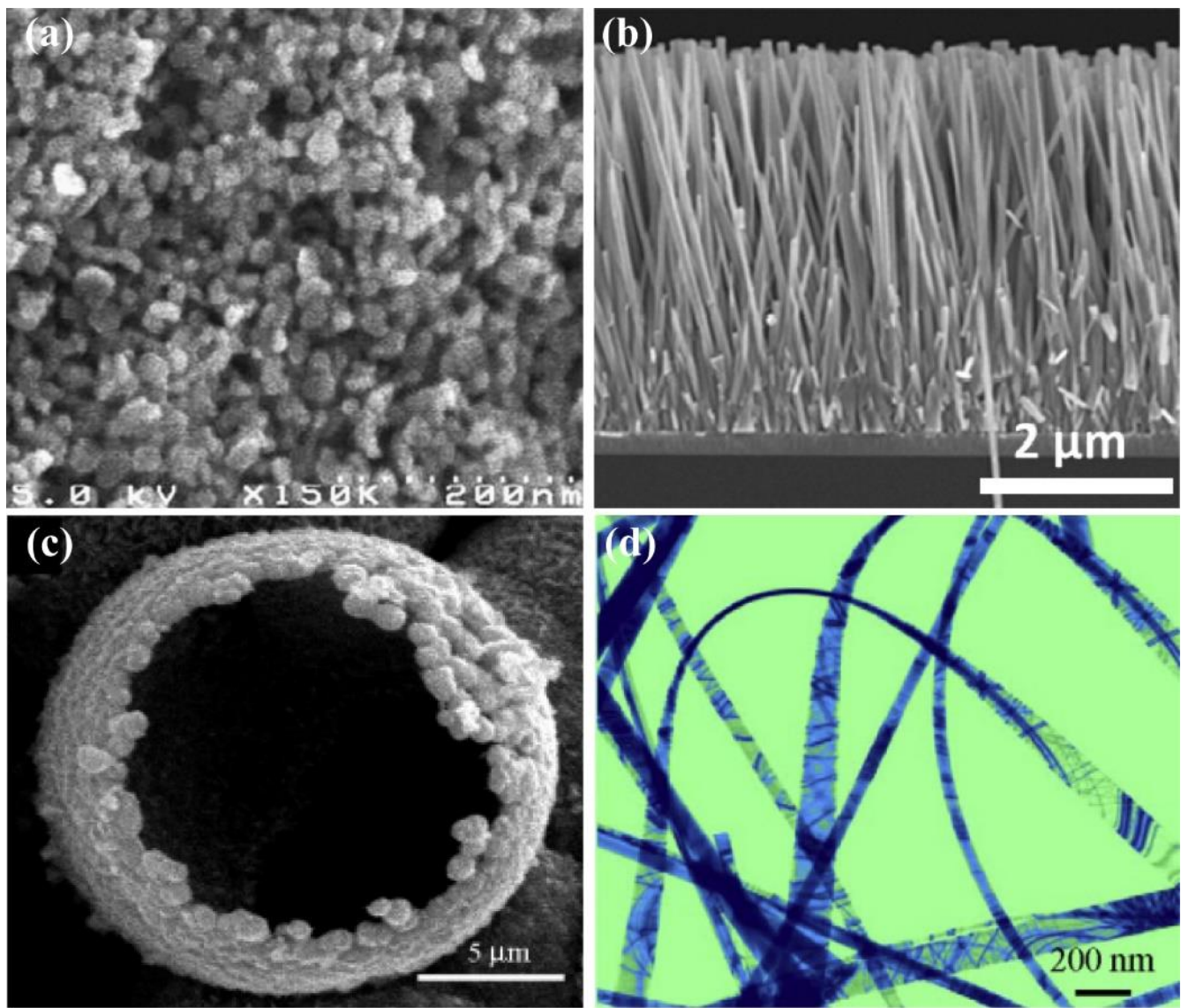

Figure 1. SEM images of ZnO nanostructures. (a) Nanoparticle. Reproduced with permission [12]. Copyright 2007, Elsevier. (b) Nanowire. Reproduced with permission [13]. Copyright 2014, Royal Society of Chemistry. (c) Hollow sphere. Reproduced with permission [21]. Copyright 2006, American Chemical Society. (d) Nanobelt. Reproduced with permission [22]. Copyright 2009, Elsevier.

These four categories of $\mathrm{ZnO}$ nanostructures tend to have different characteristics. Zero-dimensional $\mathrm{ZnO}$ nanomaterials have an obvious quantum limiting effect and the energy gap increases up to $4.5 \mathrm{eV}$ with the particle size decrease, which is beneficial to the generation and diffusion of photogenerated carriers. Therefore, they are suitable for use as photocatalytic materials and short-wavelength optoelectronic devices. One-dimensional $\mathrm{ZnO}$ nanomaterials are characterized by high aspect ratio, high mechanical strength and high thermal conductivity. The carrier migration is along the $c$-axial direction and the carrier transport speed is fast, which can effectively reduce the electron-hole composite probability and greatly improve the photoelectric conversion efficiency. In addition, the high aspect ratio makes the piezoelectric effect of one-dimensional $\mathrm{ZnO}$ more obvious and it is suitable for pressure sensors. Two-dimensional $\mathrm{ZnO}$ nanomaterials are generally oriented preferentially along the $c$-axis and they have high acoustic-electric conversion 
efficiency, which is suitable for high frequency surface acoustic wave (SAW) devices. Threedimensional $\mathrm{ZnO}$ nanomaterials usually have stereostructure and high specific surface area, which makes $\mathrm{ZnO}$ possess more hanging bonds and oxygen defects. It is helpful to improve surface activity and make it more sensitive to light and atmosphere. As a result, they are very suitable for the preparation of gas sensors and photodetectors.

With the development of miniaturization and high integration of electronic devices, it is the future trend to integrate a large number of sensors on chip, which makes the demand for nanosensor arrays increase drastically. Therefore, regular arrays of $\mathrm{ZnO}$ nanostructure have been fabricated through various synthesis methods. Figure 2 illustrates that, single $\mathrm{ZnO}$ nanowire in horizontal or vertical direction and nanoclusters can all be prepared into regular arrays, which provides a solid material basis for research on $\mathrm{ZnO}$ sensor arrays.
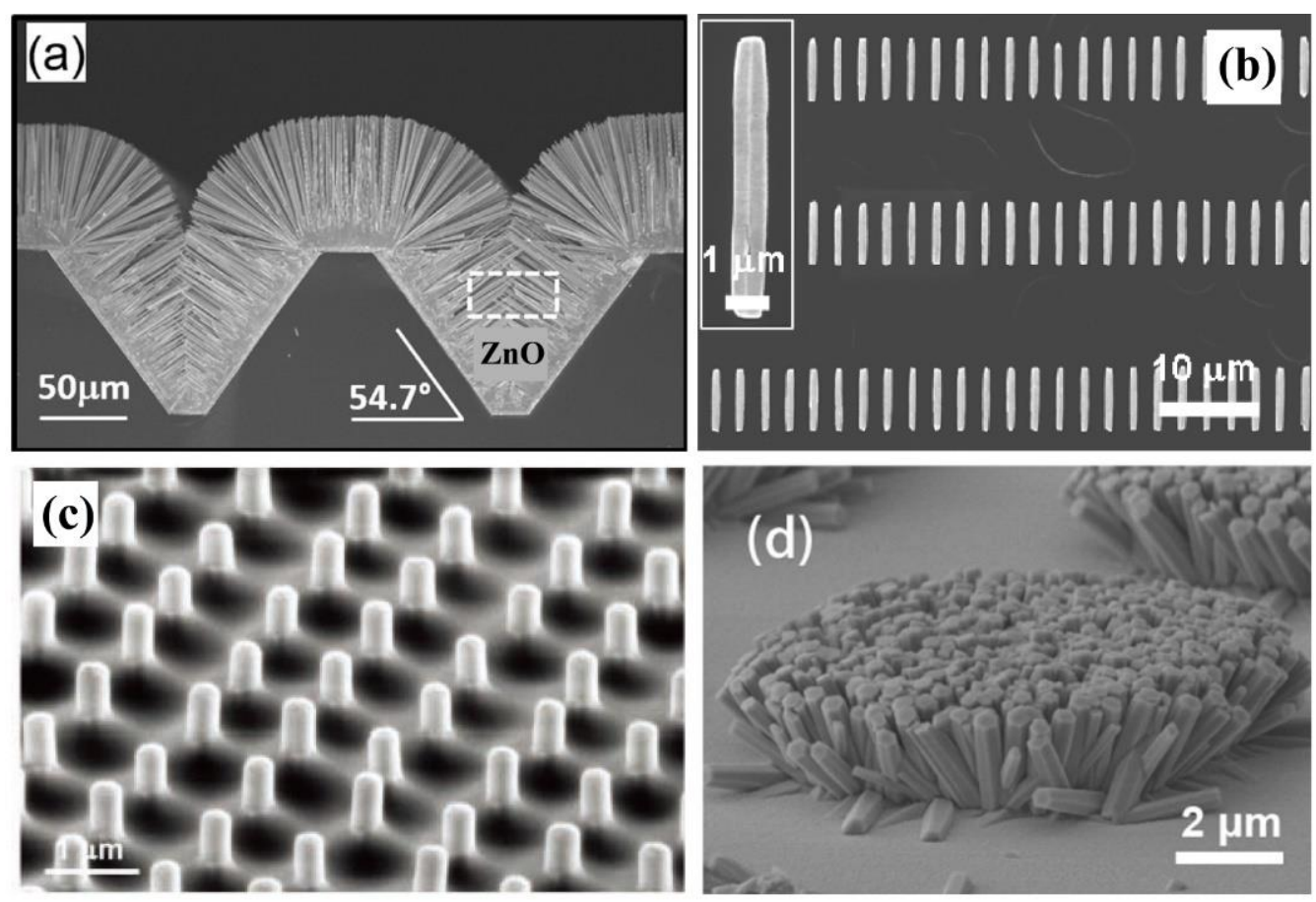

Figure 2. SEM images of $\mathrm{ZnO}$ nanostructure arrays. (a) ZnO nanocluster. Reproduced with permission [23]. Copyright 2013, American Chemical Society. (b) ZnO NR horizontal array. Reproduced with permission [24]. Copyright 2009, American Chemical Society. (c) ZnO NW vertical array. Reproduced with permission [25]. Copyright 2010, WILEY. (d) ZnO nanocluster arrays. Reproduced with permission [26]. Copyright 2015, WILEY.

$\mathrm{ZnO}$ nanomaterial used in sensors usually requires large specific surface areas, which contributes to increasing the contact area between the substance to be detected and semiconductor materials, thereby enhancing the performance of the sensors [27]. As a result, optimizing the $\mathrm{ZnO}$ nanomaterial synthesis method to further increase the specific surface area has become a hot spot in the past several years.

\subsection{ZnO Nanomaterial Synthetic Method}

There are various methods for synthesizing $\mathrm{ZnO}$ nanomaterials; the conventional means include the hydrothermal method [28], electrochemical deposition [29], magnetron sputtering deposition [30] and chemical vapor deposition [31], as well as sol-gel process [32]. Table 1 shows the comparison of some synthetic methods of $\mathrm{ZnO}$ nanomaterials.

Hydrothermal synthesis is a good approach for the synthesis of one-dimensional and two-dimensional $\mathrm{ZnO}$ nanostructures, with or without $\mathrm{ZnO}$ seeds on the substrate, which uses a precursor solution containing zinc ions and synthesizes at $60-100{ }^{\circ} \mathrm{C}$ for about $0.5-10 \mathrm{~h}$. The size and morphology of products can be controlled by adjusting the 
concentration of the solution, reaction temperature and time. The hydrothermal method has many advantages, such as environmental friendliness, simple equipment and easy operation. In addition, this method is suitable for almost all substrates, because the growth environment is mild and the growth temperature is relatively low. However, the hydrothermal method also has many shortcomings [33]. For example, crystal defects in the synthetic material are unavoidable, due to the low growth temperature.

Table 1. Synthetic methods of $\mathrm{ZnO}$ nanomaterial.

\begin{tabular}{|c|c|c|c|}
\hline Synthetic Method & Synthetic Environment & Advantage & Disadvantage \\
\hline Hydrothermal & $\begin{array}{l}\text { solution environment; } \\
\qquad 60-200^{\circ} \mathrm{C}\end{array}$ & $\begin{array}{l}\text { environmental friendliness; } \\
\text { simple equipment; } \\
\text { universality }\end{array}$ & high crystal defects \\
\hline Electrochemical deposition & $\begin{array}{l}\text { solution environment; } \\
\text { electric field }\end{array}$ & controllable thickness & nonuniform \\
\hline $\begin{array}{l}\text { Magnetron sputtering } \\
\text { deposition }\end{array}$ & $\begin{array}{l}\text { high pressure; } \\
\text { electric field }\end{array}$ & $\begin{array}{l}\text { fast deposition speed; } \\
\text { low temperature of substrate; } \\
\text { controllable thickness }\end{array}$ & $\begin{array}{l}\text { surface roughness; } \\
\text { poor uniformity; } \\
\text { uncompacted }\end{array}$ \\
\hline Chemical vapor deposition & $\begin{array}{l}\text { high pressure; } \\
\text { high temperature }\end{array}$ & high crystal quality & $\begin{array}{l}\text { high temperature } \\
\text { resistant substrate }\end{array}$ \\
\hline Sol-gel & $\begin{array}{l}\text { solution environment; } \\
\text { heat treatment }\end{array}$ & $\begin{array}{l}\text { high purity and uniform; } \\
\text { controllable particle size }\end{array}$ & $\begin{array}{l}\text { complex reaction; } \\
\text { various variables; } \\
\text { long process time }\end{array}$ \\
\hline Derive from MOF & solution environment & large surface area & impure \\
\hline
\end{tabular}

The electrochemical deposition method uses an electrolyte solution containing zinc ions in a closed loop. By applying voltage to the anode and cathode, the electron transfer and chemical reaction occur in the electrolyte solution, so that the target $\mathrm{ZnO}$ nanomaterials can be obtained on the substrate. This method is often used to synthesize $\mathrm{ZnO}$ thin film and the thickness, morphologies and the properties of deposited $\mathrm{ZnO}$ film can be controlled by adjusting the electrochemical parameters, such as the applied voltage signal, deposition time and ionic concentration [34]. However, electrochemical deposition is mostly used for the deposition of soluble substances. Due to the complexity of electrolyte and the existence of other chemical reactions in the growth of $\mathrm{ZnO}$ materials, the chemical composition of the synthetic $\mathrm{ZnO}$ nanomaterials is not uniform, which significantly affects the crystal quality of the prepared $\mathrm{ZnO}$.

The magnetron sputtering method is often used to fabricate $\mathrm{ZnO}$ film, which uses the oxygen plasma to bombard the $\mathrm{Zn}$ or $\mathrm{ZnO}$ target material, then deposits $\mathrm{ZnO}$ on the substrate. This method has the superiorities of fast deposition speed, low temperature rise of substrate, high compactness and bond strength. The morphology, thickness and properties of the prepared $\mathrm{ZnO}$ film can be controlled by regulating cavity pressure, deposition time and temperature of substrate. However, $\mathrm{ZnO}$ fabricated by magnetron sputtering also has a series of problems, such as large surface roughness, poor uniformity and insufficient compactness [35].

Chemical vapor deposition is a common method for preparing one-dimensional $\mathrm{ZnO}$ nanomaterials. It consists of heating powder of a reactant containing $\mathrm{Zn}$ at high temperature to generate $\mathrm{Zn}$ vapor and, after a series of chemical reactions, to produce $\mathrm{ZnO}$, which is deposited on the substrate. Depending on the used raw reactant materials, the reaction temperature ranges from 600 to $1200{ }^{\circ} \mathrm{C}$. The morphology and size of the $\mathrm{ZnO}$ nanostructure are affected by the synthesis temperature, pressure and the position of the substrate in the quartz tube. $\mathrm{ZnO}$ synthesized by chemical vapor deposition at high temperature tends to possess high crystal quality [36], but the high temperature process may cause damage to the substrate, which makes it unsuitable for some flexible polymer substrates [37]. 
The sol-gel method is suitable for the synthesis of zero-dimensional $\mathrm{ZnO}$ nanomaterials, in which the Zn-containing compounds are dissolved by a solution and the sol system is formed after chemical reaction, then transformed into a gel system. Finally, after dehydration and heat treatment, $\mathrm{ZnO}$ nanoparticals are produced, which possess high purity and uniform distribution and the particle size of which is controllable [32]. However, the complex reactions, various variables and long process time are the disadvantages of this method, which seriously affect the performance of $\mathrm{ZnO}$ products.

An innovative way to prepare $\mathrm{ZnO}$ nanomaterial is by means of metal-organic frameworks (MOF), which are a new type of material with large specific surface area, adjustable pore size and easy functionalization of organic ligands and skeleton metal ions. This method usually uses organic reagents and $\mathrm{Zn}^{2+}$ ion to generate an MOF-structured $\mathrm{ZnO}$ precursor; then, it is calcined at high temperature to remove organic components, thus forming the porous $\mathrm{ZnO}$ nanostructures [38,39]. Therefore, $\mathrm{ZnO}$ fabricated by this method usually possesses a large surface area, which is very suitable for the fabrication of and research on sensors. Nevertheless, the purity of $\mathrm{ZnO}$ may be seriously affected by the presence of residual organic matter.

In summary, $\mathrm{ZnO}$ nanomaterials with various morphology characteristics have been synthesized through different methods $[40,41]$. Moreover, the preparation technologies are relatively mature, after the systematic research, which provides a sound material foundation for the intensive study of $\mathrm{ZnO}$ nanosensors [42].

\section{Research Progress of ZnO Nanosensor}

$\mathrm{ZnO}$ nanostructure has excellent piezoelectric, optical and electrochemical properties. Based on different working principles, various $\mathrm{ZnO}$ nanosensors have been developed, such as pressure sensors [43], gas sensors [39], photoelectric sensors [44] and temperature sensors [45], as well as biosensors [46]. In the following sections, we will overview the recent development of $\mathrm{ZnO}$ nanosensors according to the functions and application fields $[47,48]$.

\subsection{ZnO Pressure Sensors}

\subsubsection{Mechanism of $\mathrm{ZnO}$ Pressure Sensors}

The piezoresistive and piezoelectric characteristics of $\mathrm{ZnO}$ make it particularly sensitive to pressure signals; hence, plenty of pressure sensors based on $\mathrm{ZnO}$ nanostructures have been investigated recently $[49,50]$.

When strain is applied, the energy band of $\mathrm{ZnO}$ changes, resulting in the variation of resistivity, which is the piezoresistive effect of $\mathrm{ZnO}$. A $\mathrm{ZnO}$ piezoresistive pressure sensor converts the external mechanical stimuli into electrical signals based on the piezoresistive effect and this is the mechanism of a $\mathrm{ZnO}$ piezoresistive pressure sensor [51].

$\mathrm{ZnO}$ creates a piezoelectric potential inside the crystal under external strain, due to the non-central symmetric wurtzite structure. The inner-crystal piezopotential could tune the charge generation, separation, transportation and recombination, thus affecting the electrical properties of $\mathrm{ZnO}$ devices. $\mathrm{ZnO}$ possesses a strong piezoelectric coefficient (12.4 $\left.\mathrm{pC} \mathrm{N}^{-1}\right)$, compared to other semiconductors [52], especially for $\mathrm{ZnO}$ with high quality and $\mathrm{C}$-axis preferred orientation, which has been widely used in pressure signal sensing. This is the mechanism of a $\mathrm{ZnO}$ piezoelectric pressure sensor.

\subsubsection{Progress in $\mathrm{ZnO}$ Pressure Sensors}

Pressure sensors based on $\mathrm{ZnO}$ nanomaterials have been investigated for a long time and the $\mathrm{ZnO}$ nanostructures used in pressure sensors have been gradually optimized for different application scenarios.

The earliest pressure sensor was made of $\mathrm{ZnO}$ film, since $\mathrm{ZnO}$ film can be prepared easily and it has high stability [53]. The Z. L. Wang group proposed a flexible piezoelectric pressure sensor based on $\mathrm{ZnO}$ film [54]; and they elaborated the piezotronics effect over the geometry of the as-fabricated devices and the modulation effect of piezopotential on 
charge carrier transport under different strains. However, it is difficult to achieve high sensitivity for pressure sensors based on $\mathrm{ZnO}$ film, because the piezoelectric characteristic is not obvious due to the inconsistent orientation of the crystals inside the film structure.

In contrast, one-dimensional $\mathrm{ZnO}$ exhibits superior piezoelectric properties and it is more suitable for pressure sensor. Single $\mathrm{ZnO}$ NW pressure sensors were first studied in 2013, when the Z. L. Wang group fabricated a pressure sensor based on an ultralong Sb doped p-type single $\mathrm{ZnO}$ NW, which was up to $60 \mu \mathrm{m}$ in length. They further confirmed the existence of the piezotronic effect in p-type $\mathrm{ZnO}$ NWs films and realized strain-gated piezotronic transistors [55]. Recently, the C. F. Pan group took advantage of the Sb-doped $\mathrm{p}-\mathrm{ZnO}$ NW films to achieve self-powered piezoelectric pressure sensors, which not only can detect the motion of each finger individually and accurately, but can also evaluate change in gestures based on the output signal [56], as shown in Figure 3d. Single ZnO NW and $\mathrm{ZnO}$ NW films are both proved to be high efficiency sensor materials. In addition, $\mathrm{ZnO}$ NRs are usually used in pressure sensors. Y.S. Tan et al. proposed a textile piezoelectric pressure sensor based on $\mathrm{ZnO}$ NR arrays for wearable application, which exhibited excellent performance, including a low detection limit of 8.71 $\mathrm{Pa}$, high output voltage of 11.47 V and superior mechanical stability. The sensitivity of the sensor was $0.62 \mathrm{~V} \cdot \mathrm{kPa}^{-1}$ in the pressure range of $0-2.25 \mathrm{kPa}$. Their work demonstrated that $\mathrm{ZnO}$-based wearable sensors have great application potential in the future [57].

(a)

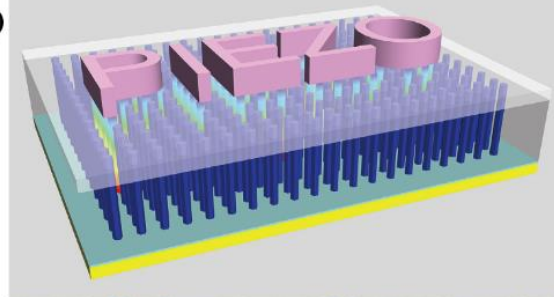

(b)

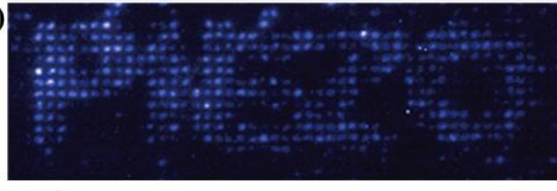

(c)

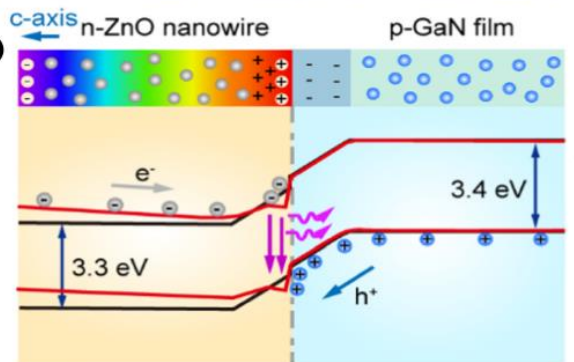

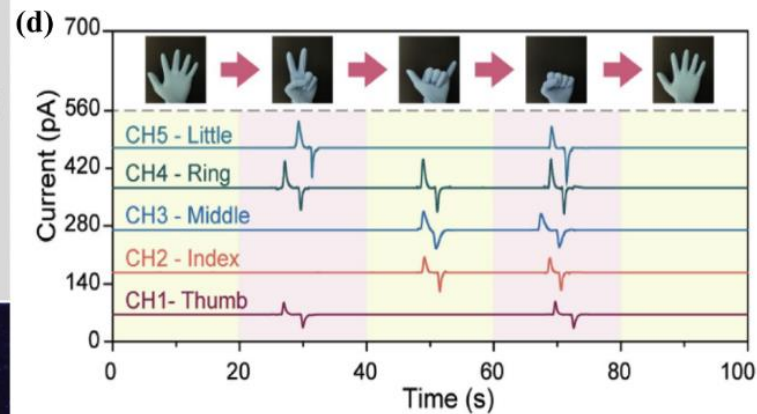

(e)

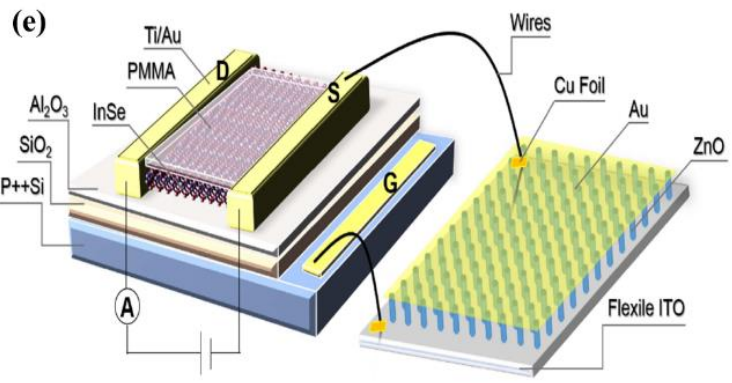

Figure 3. Pressure sensors based on $\mathrm{ZnO}$ nanostructure. $(\mathbf{a}, \mathbf{b})$ Pressure sensor based on a $\mathrm{ZnO} N W$ array on rigid GaN substrate. Reproduced with permission [58]. Copyright 2013, Nature Publishing Group. (c) Pressure sensor based on a ZnO NW array on flexible GaN substrate. Reproduced with permission [59]. Copyright 2019, Elsevier. (d) Pressure sensor based on Sb-doped p-ZnO NW films. Reproduced with permission [56]. (e) FET Pressure sensor based on ZnO NR arrays. Reproduced with permission [60]. (d,e) Copyright 2020, Elsevier.

With the development of integrated circuits and wearable electronics, pressure sensor arrays with high integration have aroused wide concern [61]. ZnO NW arrays are the preferred materials for preparing pressure sensor arrays due to their high density, high uniformity and easy adjustment. C. F. Pan et al. reported a high resolution pressure sensor based on a ZnO NW LED array, which can map two-dimensional distributions of strain and achieve an unprecedented spatial resolution of $2.7 \mu \mathrm{m}$, as shown in Figure 3a,b [58]. In 2019, this group further explored flexible pressure sensors based on $\mathrm{ZnO}$ nanowire LEDs, 
realizing a high spatial resolution of $2.6 \mu \mathrm{m}$ and a fast response time of $180 \mathrm{~ms}$ [59], as shown in Figure 3c. It still worked well after 4000 bending circles, which demonstrates that the flexible pressure sensor exhibited excellent mechanical stability. These characteristics are excellent in the field of flexible pressure sensor arrays, in addition to the advantage of the visual. Both of the above studies took advantage of the piezoelectric charges in n-type $\mathrm{ZnO}$ nanowires induced by applied strain, which could significantly affect the charge carrier separation and transport at the interface/junction of $\mathrm{ZnO} / \mathrm{GaN}$, so as to regulate the LED luminous intensity and realize the visual pressure sensor array. Their studies provided new ideas for the application of visual stress sensors with either rigid or flexible substrates.

In addition, the application of $\mathrm{ZnO}$ nanomaterials in field-effect transistors (FET) is becoming more and more mature [62]. Recently, F. L. Wang et al. fabricated flexible two-dimensional FET with ZnO NR arrays and a 2D indium selenide (InSe). The highlight of this study is that they took the piezoelectric voltage of $\mathrm{ZnO} \mathrm{NR}$ as gate potential, which can be effectively amplified by the FET, then affected the current in FET, thus realizing a pressure sensor with a sensitivity of $19.6 \mathrm{~Pa}$, corresponding to $0.1 \mathrm{~g}$ of loading [60], which was superior to that of other researches, as described in Figure 3e. Their work showed that the piezoelectric properties of $\mathrm{ZnO}$ nanostructures can be utilized in both pn structure and FET structure devices to realize pressure sensors with high performance.

\subsubsection{Discussions}

In conclusion, pressure sensors based on $\mathrm{ZnO}$ nanomaterials have experienced rapid development from thin film and single nanowire to nanowire/nanorod arrays [63]. Due to the larger aspect ratio, one-dimensional $\mathrm{ZnO}$ nanomaterials possess a more remarkable piezoelectric effect. Therefore, one-dimensional $\mathrm{ZnO}$ nanomaterials, such as $\mathrm{ZnO} \mathrm{NW}$, NR and NB, are more widely used in the field of pressure sensors. Pressure sensors based on $\mathrm{ZnO}$ NW arrays with ultra-high resolution and sensitivity have been studied maturely, which provides innovative ideas for modern applications, such as tactile sensing, human-computer interaction and measurements of stress in the micro/nano region [64]. However, there are still some problems in pressure sensors based on $\mathrm{ZnO}$ nanomaterials, such as how to optimize the synthesis method to fabricate nanostructure arrays with fewer crystal defects and higher uniformity at low temperature, which affects the performance of pressure sensors and remains a challenging technological problem.

\section{2. $\mathrm{ZnO}$ Gas Sensors}

\subsubsection{Mechanism of $\mathrm{ZnO}$ Gas Sensors}

Gas sensors play an important role in gas detection, automatic control, danger alarm and other application fields, which can convert gas information into electrical signals. According to the working mechanism, gas sensors can be divided into resistive sensors and non-resistive sensors and most $\mathrm{ZnO}$ gas sensors belong to the former. $\mathrm{ZnO}$, as an n-type semiconductor, is a key member for gas sensors, due to its superiority of low cost, low toxicity, good thermal stability and high electron mobility [65]. When the gas to be measured is adsorbed on the surface of the $\mathrm{ZnO}$ material, the resistivity of $\mathrm{ZnO}$ changes accordingly, leading to the gas-sensitive property. Especially with ZnO nanomaterials, which possess high surface-to-volume ratio, they could absorb more gas molecules on the surface, resulting in a remarkable change of surface resistance, thus making the gas sensor more sensitive. As a result, $\mathrm{ZnO}$ nanomaterials contribute to improving the performance of gas sensors significantly. ZnO materials are sensitive to carbon monoxide, ethanol, hydrogen, nitrogen dioxide and other gases [66,67]. When $\mathrm{ZnO}$ adsorbs a reductive gas, the resistivity decreases with the increase of gas concentration. On the contrary, when oxidizing gas is adsorbed, the resistivity increases with the increase of gas concentration. $\mathrm{ZnO}$ gas sensors work efficiently based on this theoretical mechanism. 


\subsubsection{Progress in $\mathrm{ZnO}$ Gas Sensors}

Various $\mathrm{ZnO}$ gas sensors have been researched extensively and the detected gases include $\mathrm{CO}, \mathrm{NO}_{2}, \mathrm{NH}_{3}, \mathrm{H}_{2} \mathrm{~S}$, ethanol, acetone, formaldehyde and so on [68,69]; according to the characteristics of the used $\mathrm{ZnO}$ materials, they can be roughly divided into conventional $\mathrm{n}$-type $\mathrm{ZnO}$ nanomaterials, specially doped $\mathrm{ZnO}$ nanomaterials and some $\mathrm{ZnO}$ complexes. In addition, some studies have shown that suitable irradiation could enhance the performance of $\mathrm{ZnO}$ gas sensors.

First, gas sensors based on conventional n-type $\mathrm{ZnO}$ have always been widely reported $[70,71]$. J. P. Meng et al. proposed a highly sensitive ethanol sensor based on Schottky junction, prepared with a single n-type $\mathrm{ZnO}$ nano/microwire (NMW); the response of the sensor was 4.8 and it was enhanced by $139 \%$ for $100 \mathrm{ppm}$ ethanol after introducing a triboelectric nanogenerator to lower the Schottky barrier height [72], as shown in Figure 4a,b. This research proves that a single $\mathrm{ZnO}$ nanowire could be manufactured as a micro/nano gas sensor with high response, which would greatly accelerate the miniaturization development of sensors. Moreover, their work introduces an effective method to improve the responsiveness of gas sensors by using a triboelectric nanogenerator, which provides an innovative idea for the development of other types of sensors.

In order to improve the performance of gas sensors, some specially doped $\mathrm{ZnO}$ nanomaterials have been proved to exhibit excellent gas sensing properties [73]. A number of studies have shown that $\mathrm{Cu}$ - or Pt-doped $\mathrm{ZnO}$ nanostructures are sensitive to $\mathrm{H}_{2}[74,75]$ and $\mathrm{Au}$-, Ag- or $\mathrm{Pd}$-doped $\mathrm{ZnO}$ nanostructures are sensitive to ethanol and acetone [76,77]. Recently, T. Dilova et al. compared the gas sensors fabricated with pure and a palladium (Pd)-doped $\mathrm{ZnO}$ nanobelt [78]. As shown in Figure 4d, the results showed that the $\mathrm{Pd}-\mathrm{ZnO}$ nanosensor showed a better response to $\mathrm{CO}, \mathrm{NH}_{3}$ and acetone than the pure $\mathrm{ZnO}$ sample, which mainly owes to the Pd nanoparticles decorated on the $\mathrm{ZnO}$ surface increased number of adsorption centers. In the same year, they prepared nanosensors with highly porous pure and silver (Ag)-doped $\mathrm{ZnO}$ nanostructures and studied their response to $\mathrm{NH}_{3}, \mathrm{CO}$, ethanol and acetone under the irradiation of ultraviolet light and infrared light. It was found that when the infrared light was irradiated, the response of the sensor to CO was obviously enhanced, but the response to acetone and ethanol was weak, as shown in Figure 4e [79]. Under the irradiation of an ultraviolet light intensity of $43 \mathrm{MW} \mathrm{cm}^{-2}$, the sensor had the highest response to acetone and ethanol and the lowest response to $\mathrm{CO}$. They also studied the influence of ultraviolet and red irradiation on the response and response recovery time of sensor components. The results showed that ultraviolet and optimized red irradiation enhanced the response of the $\mathrm{Ag}-\mathrm{ZnO}$ sensor to $\mathrm{CO}$, while suppressing its response to $\mathrm{NH}_{3}$, ethanol and acetone. Moreover, the sensor showed a strong and stable response signal under a $\mathrm{CO}$ concentration of $1 \mathrm{ppm}$, which indicates that a low concentration of $\mathrm{CO}$ can be detected by simultaneous irradiation of ultraviolet light and infrared light. Their work mainly verified the influence of light irradiation on the performance of gas sensors, which lay the research foundation for the development of high performance and multi-function sensors.

In addition, the research on the $\mathrm{ZnO}$ complex for gas sensing is increasingly extensive. H. T. Wang et al. fabricated a sensor with a $\mathrm{ZnO} / \mathrm{g}-\mathrm{C}_{3} \mathrm{~N}_{4}$ composite and studied its sensing performance for $\mathrm{NO}_{2}$ under different wavelength LED light sources, as shown in Figure 4c [80]. Under the illumination of $460 \mathrm{~nm}$ wavelength, the maximum response of $\mathrm{ZnO} / \mathrm{g}-\mathrm{C}_{3} \mathrm{~N}_{4}$ to $7 \mathrm{ppm} \mathrm{NO} \mathrm{N}_{2}$ was 44.8 and the detection limit was $38 \mu \mathrm{g} \mathrm{L}^{-1}$, with a response time of $142 \mathrm{~s}$ and recovery time of $190 \mathrm{~s}$. The highlight of this research is that sensors with $\mathrm{ZnO} / \mathrm{g}-\mathrm{C}_{3} \mathrm{~N}_{4}$ composites exhibited better selectivity and high stability, which is attributed to the absorbance of $\mathrm{g}-\mathrm{C}_{3} \mathrm{~N}_{4}$ in the visible light region and the charge separation at the interface between $\mathrm{ZnO}$ and g- $\mathrm{C}_{3} \mathrm{~N}_{4}$. F. F. Cao et al. compounded carbon nanotubes (CNT) on $\mathrm{ZnO}$ nanorods ( $\mathrm{ZnONR}$ ) by ultrasonic dispersion and studied two kinds of gas sensors prepared with ZnONR and ZnONR/CNT, respectively [81]. They found that these two kinds of gas sensor exhibited good selectivity, stability and reproducibility for $0.01 \%$ mass fraction of ethanol at $370{ }^{\circ} \mathrm{C}$ and, in contrast, sensors with ZnONR/CNT showed superior 
performance due to the hollow tubular structure, which greatly increases the surface area of nanomaterials. These studies declared that by combining $\mathrm{ZnO}$ with other nanomaterials with a high specific surface area, the gas absorbance can be further increased, which is an effective way to improve the sensitivity and response of $\mathrm{ZnO}$ gas sensors.
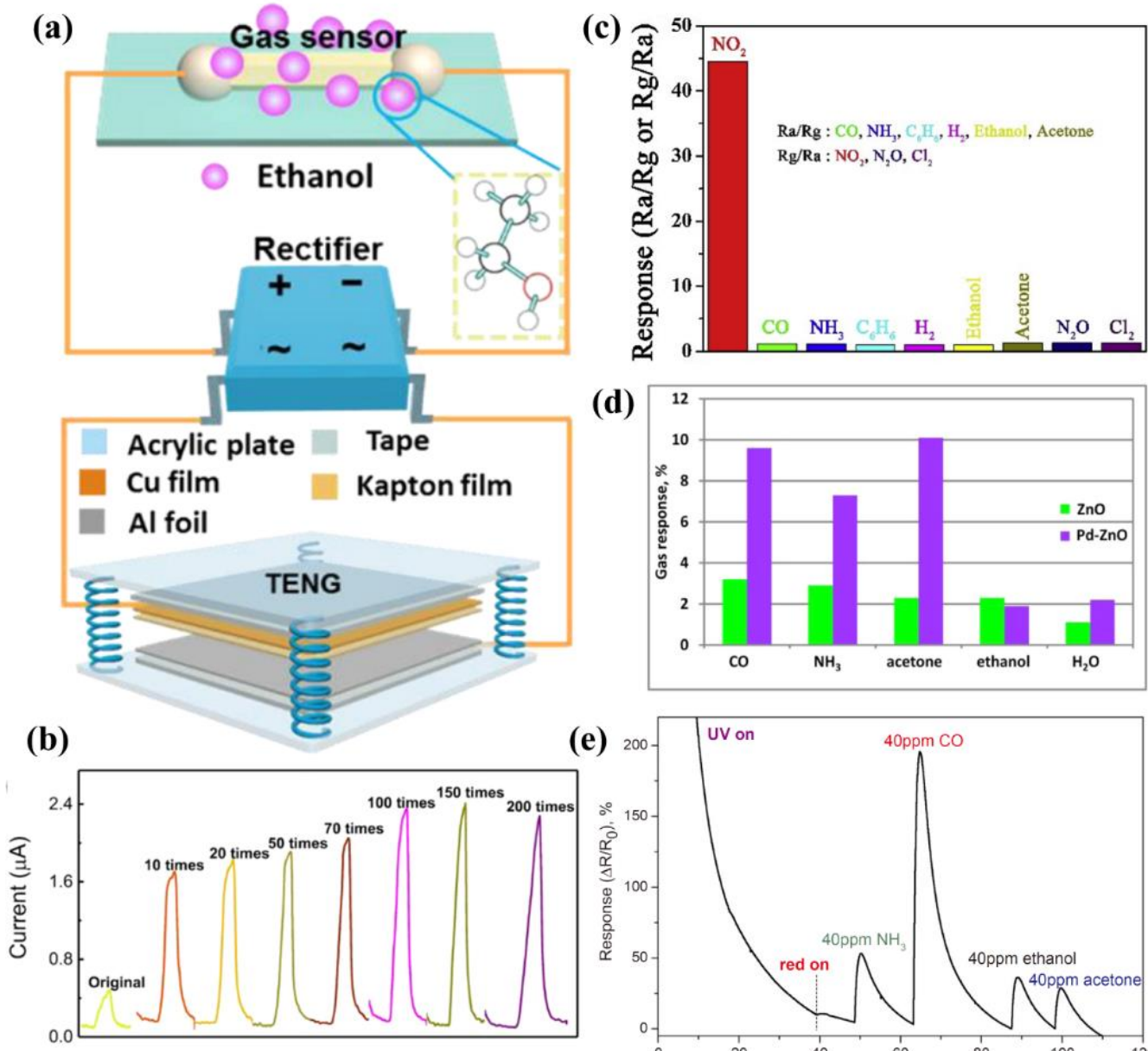

(d)

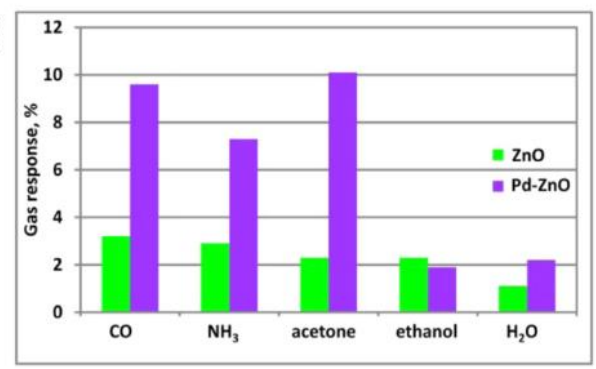

(e)

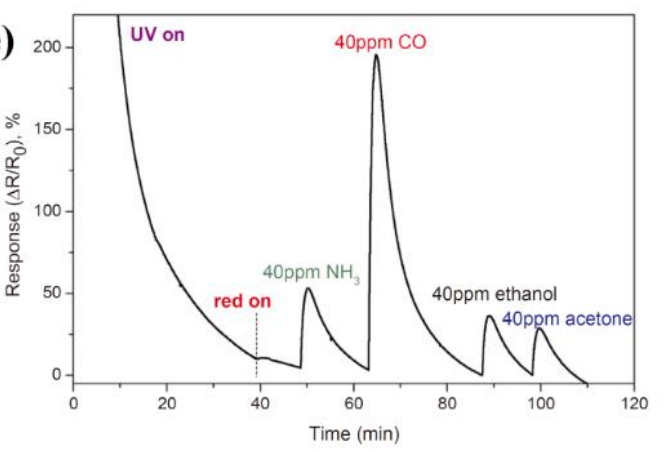

Figure 4. Gas sensors based on $\mathrm{ZnO}$ nanostructure. (a,b) ZnO NMW gas sensor for ethanol. Reproduced with permission [72]. (c) $\mathrm{ZnO} / \mathrm{g}-\mathrm{C}_{3} \mathrm{~N}_{4}$ composite gas sensor for $\mathrm{NO}_{2}$. Reproduced with permission [80]. (d) Pd-ZnO gas sensor. Reproduced with permission [78]. (e) Irradiation-assisted gas sensor. Reproduced with permission [79]. Copyright 2020, Elsevier.

\subsubsection{Discussions}

In brief, gas sensors based on $\mathrm{ZnO}$ nanomaterials show excellent properties and, through combining with other nanomaterials with high specific surface areas or embellished with metallic elements, $\mathrm{ZnO}$ exhibits increased surface area, which helps to improve the response of the gas sensor [82]. High selectivity, which means that they can accurately identify the target gas to be measured in complex mixed atmosphere, is an important parameter for gas sensors. The selectivity of $\mathrm{ZnO}$ gas sensors can be improved effectively by modifying the surface of $\mathrm{ZnO}$ materials with functional groups or metals. In addition, the proper irradiation could also affect the sensitivity of $\mathrm{ZnO}$ gas sensors, due to the change in the vacancy stage introduced by irradiation. $\mathrm{ZnO}$ gas sensors have attracted much attention due to simple preparation, stable properties and good compatibility [83]. However, gas sensors based on $\mathrm{ZnO}$ nanostructures still face many obstacles, such as high working temperature, high resistivity, poor selectivity and low sensitivity. Hence, there is still a lot of work to be conducted for the realization of gas nanosensors with superb performance in the future. 


\section{3. $\mathrm{ZnO}$ Photoelectric Sensors}

\subsubsection{Mechanism of $\mathrm{ZnO}$ Photoelectric Sensors}

Photoelectric sensors can convert optical signals into electrical signals and have been widely used in industrial automation and robots due to the advantages of non-contact, fast response and high precision. Various photoelectric sensors have been proposed, mainly including infrared (IR) sensors, ultraviolet (UV) sensors and visible wavelengths sensors, according to the working wavelength [84].

Due to the wide bandgap, low cost and simplicity in manufacturing process, $\mathrm{ZnO}$ has become a potential semiconductor for photoelectric sensors and it has aroused extensive investigations $[85,86]$. When under illumination, as long as the photon energy is larger than the bandgap width of $\mathrm{ZnO}$, the electrons in the valence band could absorb the energy of the photon, then transition to the conduction band, generating additional free electrons and holes. The resistivity of $\mathrm{ZnO}$ semiconductors becomes smaller due to the photogenerated carriers, which affects the electrical signals in the photoelectric device. This is the mechanism of $\mathrm{ZnO}$ photoelectric sensors. According to their typical wide bandgap $(3.37 \mathrm{eV})$ and large exciton binding energy $(60 \mathrm{meV}), \mathrm{ZnO}$ nanostructures are suitable for detecting UV light [87]. In addition, $\mathrm{ZnO}$ nanomaterials are usually used to prepare infrared photoelectric sensors because of their high electron mobility and regular nanostructures.

\subsubsection{Progress in $\mathrm{ZnO}$ Photoelectric Sensors}

\section{UV Photoelectric Sensor}

In recent years, $\mathrm{UV}$ photoelectric sensors based on $\mathrm{ZnO}$ nanomaterials have received more and more attention, including $\mathrm{ZnO}$ films, single $\mathrm{ZnO} \mathrm{NW}, \mathrm{ZnO}$ NW arrays and $\mathrm{ZnO}$ complexes. Then, we display a brief introduction to the UV photoelectric sensors according to the morphology of $\mathrm{ZnO}$ nanomaterials.

UV photoelectric sensors based on $\mathrm{ZnO}$ film have been investigated widely. Recently, $\mathrm{M}$. Cavas et al. investigated two types of photoelectric sensors based on pure $\mathrm{ZnO}$ film and Ga-doped $\mathrm{ZnO}$ film on a p-Si substrate, respectively. The results of their research show that the bandgap of $\mathrm{ZnO}$ varies with Ga doping concentration, which has a great influence on the photoelectric performance of the device. They proved that the optimal Gadoping ratio is $5 \%$ and the UV photoelectric sensor represents the best photoelectric sensing characteristics, compared with that of devices in other doping ratios [87]. M. B. Jeon et al. demonstrated a port-resonator-types of UV sensor consisting of Ag NW and ZnO thin film bi-layer, with a resonance frequency of $243.15 \mathrm{MHz}$. Their research proved that the UV irradiation-generated photocurrent influences the acoustic-electric effect of the SAW sensor, as shown in Figure $5 \mathrm{~b}$ [88]. Compared to sensors with a $\mathrm{ZnO}$ single thin film, bi-layer structure sensors exhibited a more excellent response and recovery characteristics, due to the electron trap center within the $\mathrm{ZnO}$ film compensated by the $\mathrm{AgNW} / \mathrm{ZnO}$ structure and the larger surface area for oxygen adsorption. 
(a)

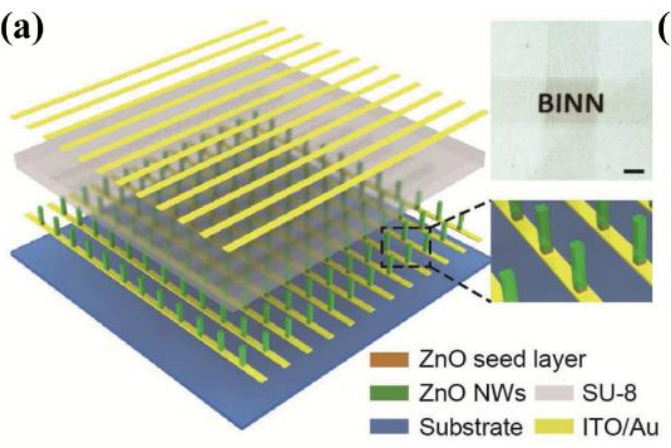

(c)

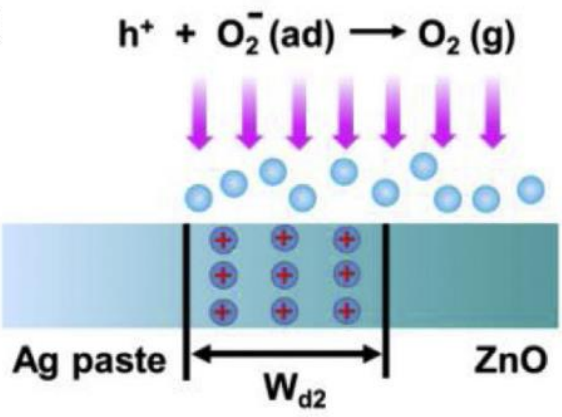

(d) (b)
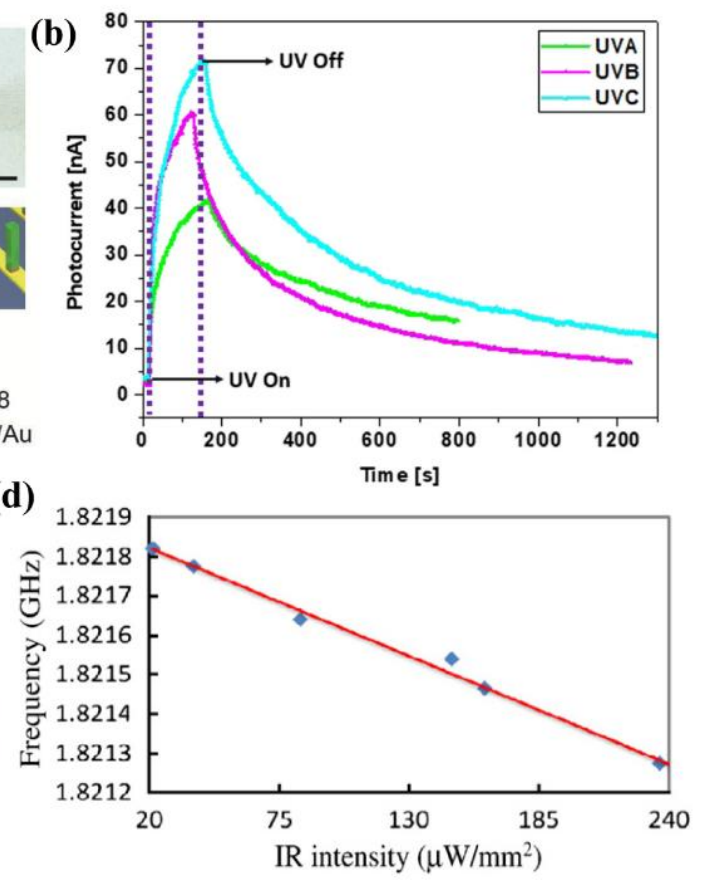

Figure 5. Photoelectric sensors based on $\mathrm{ZnO}$ nanostructures. (a) $\mathrm{ZnO} \mathrm{NW}$ UV sensor arrays. Reproduced with permission [89]. Copyright 2015, WILEY. (b) ZnO bi-layer structure UV sensors. Reproduced with permission [88]. Copyright 2020, Elsevier. (c) ZnO UV sensor based on Schottky junction. Reproduced with permission [90]. Copyright 2020, Elsevier. (d) IR sensor based on ZnO film. Reproduced with permission [91]. Copyright 2011, Elsevier.

$\mathrm{ZnO} \mathrm{NW}$ is a good material for preparing photoelectric sensors and a number of studies have been reported in recent years [92,93]. H. Li et al. reported a UV sensor based on the Schottky barrier height (SBH) of single ZnO NW and Ag paste, as illustrated in Figure $5 c$ [90]. Moreover, they further enhanced the response characteristics through lowering the SBH using triboelectric voltage, thus finally achieving a raising edge of $1.05 \mathrm{~s}$, a falling edge of $0.38 \mathrm{~s}$ and an on/off ratio of up to 10,400. This work presented a simple structure of UV sensors based on single $\mathrm{ZnO} N W$ with excellent response and proposed an innovative method to improve its performance. In addition, $\mathrm{UV}$ sensors based on $\mathrm{ZnO}$ NW arrays have been deeply studied. Recently, C. F. Pan et al. proposed a ZnO NW UV sensor arrays consisting of $32 \times 40$ pixels, with spatial resolution of $100 \mu \mathrm{m}$ ( $254 \mathrm{dpi}$ ); when under $3.95 \mathrm{~mW} \mathrm{~cm}^{-2}$ UV illumination, the measured response time was $62 \mathrm{~ms}$, as shown in Figure 5a [88]. Then, they improved the performance of the UV sensor by introducing the piezo-phototronic effect, including a 700\% increase in photoresponsivity and $600 \%$ increase in sensitivity. In this study, UV sensor arrays with high responsiveness were successfully realized by using both photoelectric and piezoelectric characteristics of $\mathrm{ZnO}$ NWs.

$\mathrm{ZnO}$ complexes have been used in the field of photoelectric sensors and present splendid properties. Y. F. Zhao et al. fabricated three types of UV sensors using pure $\mathrm{NaTaO}_{3}, \mathrm{ZnO}$ and their composites, respectively [94]. Among them, a UV sensor based on 1:1 $\mathrm{NaTaO}_{3} / \mathrm{ZnO}$ displayed the most outstanding photoelectric performance, including a low dark current, a high photo-to-dark current ratio and a stable periodic photoresponse. Their research showed that a $\mathrm{ZnO}$ compound with appropriate proportions has a potential application value in improving the performance of photoelectric sensors.

\section{IR Sensor}

In addition to the UV photoelectric sensor, IR sensor based on $\mathrm{ZnO}$ nanomaterials have aroused wide concern recently $[95,96]$. $\mathrm{ZnO}$ nanostructures mainly act as an electron transport layer or an optical resonator with high quality in these photoelectric sensors. 
Recently, J. B. Kwon et al. provided a shortwave infrared (SWIR) sensor based on lead chloride quantum dots (PbS QDs) and ZnO NPs, in which PbS QDs worked as the photoactive layer and $\mathrm{ZnO}$ NPs worked as the electron-transport layer [85]. It was found, by comparing PbS SWIR sensors with and without a $\mathrm{ZnO}$ NPs layer, that the former exhibited higher on/off ratio and more stable current characteristics, due to the high electron mobility and the lowest unoccupied molecular orbital level of ZnO NPs.

In addition, Z. Y. Wang et al. fabricated a film bulk acoustic resonator (FBAR) based on $\mathrm{ZnO}$ thin film. Figure $5 \mathrm{~d}$ shows that the resonant frequency of FBAR was linearly related to infrared light intensity under the irradiation of infrared light and the resonant frequency decreased with the increase in infrared light intensity. This is because the Young's modulus of the $\mathrm{ZnO}$ resonator is affected by temperature, thus leading to the shift in resonant frequency. Their study confirmed the feasibility of FBAR as a potential infrared detector, which shows an excellent response to infrared light [91].

\subsubsection{Discussions}

A large number of experiments has proved that $\mathrm{ZnO}$ nanostructure is one of the ideal materials for preparing photoelectric sensors. No matter whether it is pure $\mathrm{ZnO}$ nanostructure, doped $\mathrm{ZnO}$ nanomaterials, or $\mathrm{ZnO}$ composite materials, they all exhibit favorable photoelectric properties. Although the energy band of $\mathrm{ZnO}$ only corresponds to the UV light wavelength, $\mathrm{ZnO}$ can also play an important role as an electron transfer layer in the photoelectric sensor for other light wavelength ranges. For example, the Z. L. Wang group demonstrated a flexible visible/UV photodetector, which consisted of a ZnO-CdS double-shell NW array and carbon fiber. It presented ultrahigh response to blue, green and UV light; in addition, the responsivity was enhanced by $60 \%$ under a $-0.38 \%$ compressive strain due to the piezopotential in $\mathrm{ZnO}$ [97]. Their study verified that $\mathrm{ZnO}$, as preferred material for photoelectric sensor, not only has a wide sensitive band, but also possesses piezoelectric characteristics, which could help improve the photoelectric sensing performance.

However, photoelectric sensors based on $\mathrm{ZnO}$ still face some pressing problems, such as the high resistivity of $\mathrm{ZnO}$, which leads to a low photocurrent and poor detection performance of the photoelectric sensor [98]. Moreover, the question of how to break through the limitation that the band gap of $\mathrm{ZnO}$ just corresponds to the ultraviolet band, which is a tough problem, needs to be solved. In addition, the sensitivity to light largely depends on the shape and size of the $\mathrm{ZnO}$ nanostructure [99], but the research on different morphologies and structures of $\mathrm{ZnO}$ is still immature, which is also a major factor restricting the application of $\mathrm{ZnO}$-based photoelectric sensors.

\section{4. $\mathrm{ZnO}$ Biosensors}

\subsubsection{Mechanism of $\mathrm{ZnO}$ Biosensors}

In recent years, biosensors have attracted extensive attention from all walks of life and have been widely used in the detection of protein, hormones and peptides [100]. The mechanism of biosensors is that when the molecules to be detected enter the bioactive material through diffusion, a biological reaction occurs and the generated information is converted into electrical signals to instruct the concentration of the substance to be measured [101]. ZnO nanomaterials are commonly used in biosensors, since they possess outstanding biocompatibility, electron transfer characteristics, wide bandgap, large surface area and mature synthesis techniques [102]. In general, $\mathrm{ZnO}$ plays the role of increasing the adsorption area of biomolecules and promoting electron transfer in biosensors, which can effectively improve the responsivity and sensitivity of biosensors.

\subsubsection{Progress in $\mathrm{ZnO}$ Biosensor}

Biosensors based on $\mathrm{ZnO}$ nanomaterials have been widely studied recently [103] and, next, we provide a brief introduction to biosensors according to the morphology of $\mathrm{ZnO}$ in the biosensor. 
Zero-dimensional $\mathrm{ZnO}$ nanomaterials have been proved to be a suitable material for biosensors. U. D. Kamaci et al. demonstrated a ZnO QDs-based fluorescent biosensor for detection of cysteine in different solutions, which exhibited a high selectivity and responsivity [104]. Another research used $\mathrm{ZnO} / \mathrm{NiO} / \mathrm{Al}_{2} \mathrm{O}_{3}$ nanoparticles to realize an enzyme-less l-glutamic acid (L-GA) sensor with superior sensing performance [100]. These studies show that zero-dimensional $\mathrm{ZnO}$ nanomaterials play an important role in biosensors due to their large surface area.

Single $\mathrm{ZnO}$ NW has been investigated to form efficient biosensors. L. M. Zhao et al. proposed a highly sensitive multifunctional biosensor based on Schottky and Ohmic reversible (SOR) structures, which can convert between Schottky and Ohmic contact tuned by triboelectric nanogenerator (TENG) due to the diffusion of oxygen vacancies in $\mathrm{ZnO}$ nano/micro wire (NMW) when it is driven by TENG voltage pulses [105], as shown in Figure $6 \mathrm{a}, \mathrm{b}$. In the Schottky contact state, the biosensor is sensitive to low concentration of dopamine $\left(0.1 \mu \mathrm{mol} \mathrm{mL}^{-1}\right)$, while, in the ohmic contact, it exhibits sensitivity to neural electric impulses. Therefore, this work demonstrated a comprehensive multifunctional sensor, which will broaden the application of biosensors for brain science and clinical diagnosis.

(a)

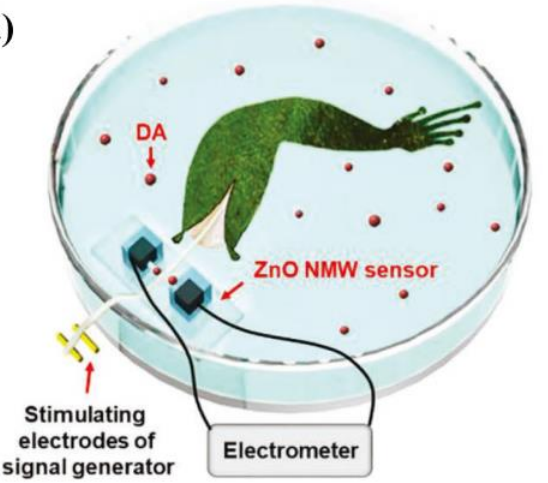

(c)

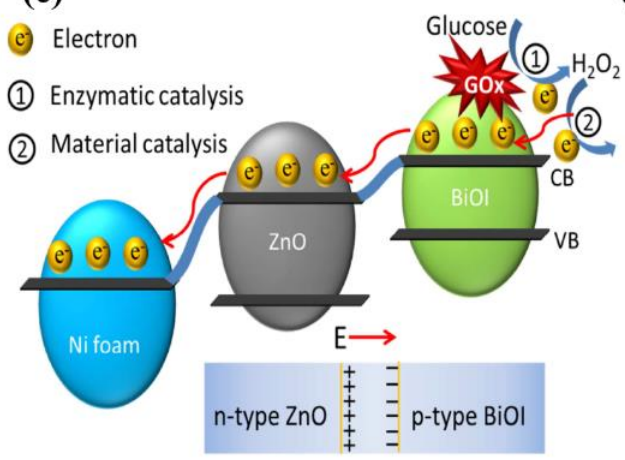

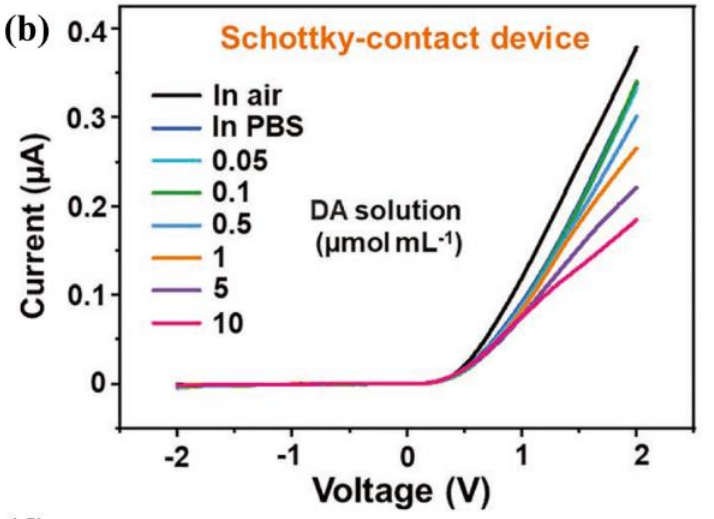

(d)

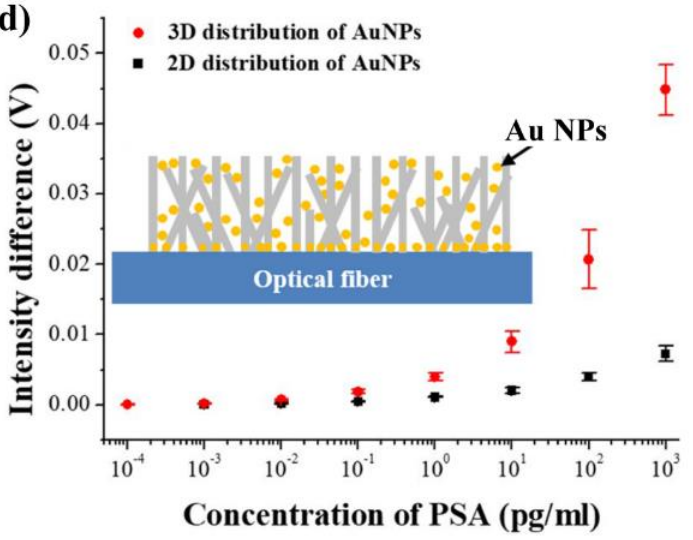

Figure 6. Biosensors based on $\mathrm{ZnO}$ nanostructure. $(\mathbf{a}, \mathbf{b}) \mathrm{ZnO} N M W$ biosensor for dopamine. Reproduced with permission [105]. Copyright 2019, WILEY. (c) ZnO/BiOI core-shell biosensor for glucose. Reproduced with permission [106]. Copyright 2020, Elsevier. (d) ZnO NWs biosensor for PSA. Reproduced with permission [107].

$\mathrm{ZnO}$ NW arrays have been proved to be a suitable material in biosensors. H. M. Kim et al. fabricated a highly sensitive plasmonic biosensor based on three-dimensional (3D) structures composed of optical fiber, $\mathrm{ZnO}$ NWs and Au NPs [107]. Compared with biosensor with 2D structures, the sensitivity to prostate-specific antigen (PSA) of 3D biosensors was improved notably, as illustrated in Figure 6d. This is because the introduced $\mathrm{ZnO}$ NWs helped focusing light on the sensing region due to its forest-like structural characteristics and enhancing the surface area for attaching Au NPs. Furthermore, the porous structure 
of $\mathrm{ZnO}$ NWs constitutes a fast channel for target molecules accessing the surface of the $\mathrm{Au}$ NPs.

In addition, the $\mathrm{ZnO}$ complex is one of the most suitable materials for biosensors. M. G. Zhao et al. reported a glucose biosensor composed of $\mathrm{Ni}$ foam and the $\mathrm{ZnO} / \mathrm{BiOI}$ core-shell p-n junction nanorods, which played an important role in working as an enzyme loading matrix for detecting glucose, as described in Figure 6c [106]. The composite structures contributed to enhancing the performance of the biosensor, with an enhanced sensitivity of $115.2 \mu \mathrm{A} \cdot \mathrm{mM}^{-1} \cdot \mathrm{cm}^{-2}$ and a decreased detection potential of $0.3 \mathrm{~V}$, because it provided multiple catalysis and the porous surface helped loading more enzymes. Another significant advantage of this design structure is that the p-n junction accelerated electron transport due to the existence of the built-in electric field and the electron well. Another research carried out by S. Pal et al. demonstrated a DNA hybridization biosensor based on surface plasmon resonance (SPR), consisting of a SF10 prism-Au-ZnO-Graphene-PBS solution [108]. Since both $\mathrm{ZnO}$ and graphene possess excellent chemical stability, light absorption capability and biocompatibility, the DNA hybridization biosensor presented outstanding sensitivity.

\subsubsection{Discussions}

Numerous studies have demonstrated that the combination of $\mathrm{ZnO}$ nanostructures and biosensors not only broadens the application field of semiconductor nanomaterials, but also promotes the development of biosensor technology in various fields $[109,110]$. For example, the composite of $\mathrm{Ag}$ and $\mathrm{ZnO}$ nanomaterial exhibited good antibacterial property and the composite materials of $\mathrm{ZnO}$ doped with graphene were applied to the detection of special DNA. Although $\mathrm{ZnO}$ could greatly promote electron transfer in biosensors, there are still some bottlenecks for the $\mathrm{ZnO}$ biosensors. One of the severe problems is that the surface control of $\mathrm{ZnO}$ nanomaterial and the fusion with other doping materials have a great influence on the sensitivity of the sensor, which significantly limits the development of $\mathrm{ZnO}$-based biosensors. Therefore, on the one hand, enhancing the characteristics of $\mathrm{ZnO}$, such as further increasing its specific surface area and electron transfer rate, and, on the other hand, improving the integration between $\mathrm{ZnO}$ and other materials, especially bio-organic materials, are the scientific problems to be explored for $\mathrm{ZnO}$ biosensors in the future. Improving the stability, repeatability, selectivity and sensitivity of the biosensor by the surface modification method has been the main research of $\mathrm{ZnO}$ biosensors in the past few decades and it remains to be the focus of future research. It is a significant challenge to explore and discover the sensitivity of different $\mathrm{ZnO}$ structures to various biological systems and to realize biosensors with more functions, so as to provide a theoretical basis for the development of health care and detection field.

\subsection{ZnO Temperature Sensors}

\subsubsection{Mechanism of $\mathrm{ZnO}$ Temperature Sensors}

A temperature sensor converts the temperature signal into an electrical signal and its working principle is that the resistance value and the potential of the thermocouple change regularly with the variation of temperature. Thus, temperature information can be displayed by monitoring the electrical signals, since the carrier concentration and the energy gap of $\mathrm{ZnO}$ changes with temperature, resulting in regular variation of electrical properties accordingly. Therefore, $\mathrm{ZnO}$ is an excellent material suitable for preparing temperature sensors, which have been investigated for a long time [111].

\subsubsection{Progress in $\mathrm{ZnO}$ Temperature Sensor}

In recent years, temperature sensors based on $\mathrm{ZnO}$ have been proposed successively [112], including sensors based on $\mathrm{ZnO}$ nanostructures, $\mathrm{ZnO}$-decorated optical fiber and SAW devices. Here, we give a brief overview of these $\mathrm{ZnO}$ temperature sensors, respectively. 


\section{ZnO Nanostructures Temperature Sensor}

$\mathrm{ZnO}$ nanomaterials with various morphologies have been widely used in the preparation of temperature sensors. F. Xue et al. demonstrated a flexible temperature sensor based on $\mathrm{ZnO}$ NW film, which was fabricated by wet chemical deposition, as shown in Figure 7a [113]. Piezopotential in $\mathrm{ZnO}$ NW film contributed to enhancing the sensitivity of the sensor and the red line in Figure $7 \mathrm{~b}$ indicates that the response current of the sensor decreased as the temperature increased from 10 to $110^{\circ} \mathrm{C}$. This is because the piezoelectric effect increases the Schottky barrier, which reduces the current in the temperature sensor. The blue line shows the relative current change, which indicates a well response of this temperature sensor. Their work provided a simple temperature sensor model and an effective method to improve the performance of $\mathrm{ZnO}$ temperature sensors.

(a)

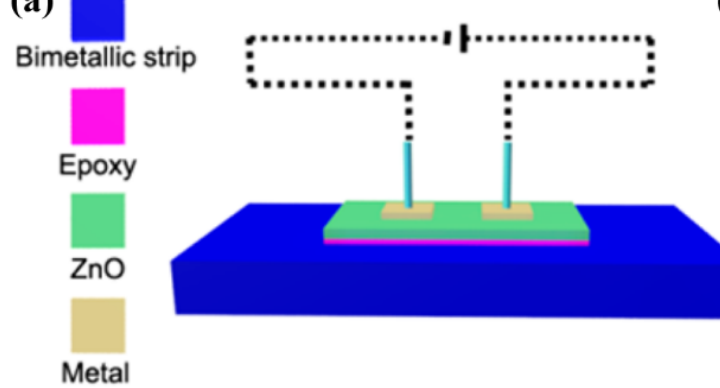

(c)

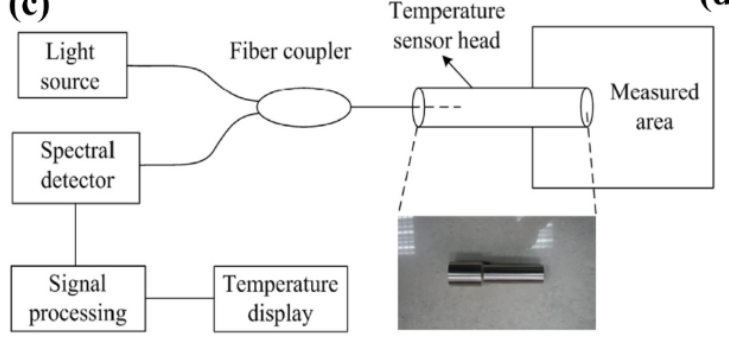

(b)

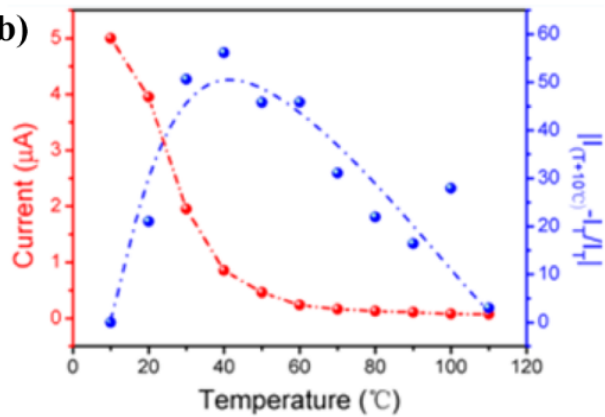

(d)

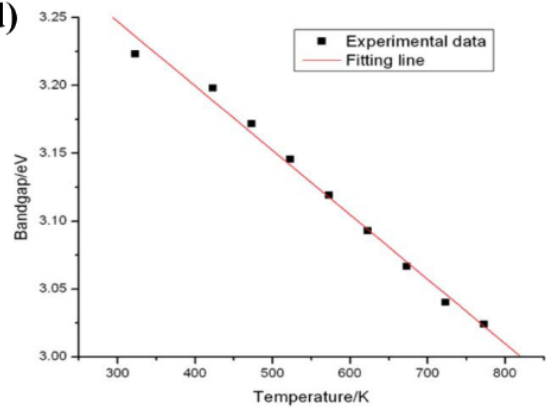

Figure 7. Temperature sensors based on $\mathrm{ZnO}$ nanostructure. $(\mathbf{a}, \mathbf{b})$ Flexible temperature sensor based on ZnO NW film. Reproduced with permission [113]. Copyright 2014, American Chemical Society. (c,d) Fiber optical temperature sensor based on $\mathrm{ZnO}$ NW film. Reproduced with permission [114]. Copyright 2014, Elsevier.

In addition, G. H. Hui et al. used $\mathrm{ZnO}$ nanoparticles and $\mathrm{Au}$ interdigital electrodes to realize a temperature sensor [115]. The results show that the current decreased with the temperature increase, due to the reduction of electrical carrying body, including oxygenic cavity and $\mathrm{Zn}$ spacing. Furthermore, the temperature sensor presented excellent sensitivity and repeatability. Their research proved that the defect states in $\mathrm{ZnO}$ could improve the sensing performance of the temperature sensor to some extent.

\section{ZnO SAW Temperature Sensor}

SAW temperature sensors based on $\mathrm{ZnO}$ are one of research hotspots [116]. A flexible SAW temperature sensor was reported by S. A. Hasan et al., composed of $\mathrm{ZnO}$ thin film and aluminium (Al) foil [117]. The device was measured on a printed circuit board (PCB), which can be flat or curved. The research proved that the flexible sensor steadily exhibited high sensitivity in both flat and curved conditions, which declares the excellent mechanical stability of the sensor and the application prospect in the wearable temperature sensing electronics. Another SAW temperature sensor made of $\mathrm{ZnO}$ and $\mathrm{LiNbO}_{3}$ substrate was reported by H. Yamamoto [118] and it showed that the temperature dependence on frequency exhibited linear characteristics. In conclusion, SAW temperature sensors 
based on $\mathrm{ZnO}$ possess good performance and they provide new ideas for the study of temperature sensors.

\section{ZnO Optical Fiber Temperature Sensor}

Fiber optic temperature sensors have wide application prospects in industrial production, aerospace and other fields, due to the advantages of low loss over long distances, flexibility, small size and light weight of optical fiber. Optical fiber temperature sensors with $\mathrm{ZnO}$ nanostructures have aroused research interest recently; they can measure the temperature by detecting the transmission spectrum and observing the movement of the absorption edge. They have the advantages of simple structure, convenient operation, low cost and wide temperature range.

Recently, H. L. Wang et al. proposed a fiber optical temperature sensor employing the spectral absorption effect of $\mathrm{ZnO}$ thin film, with a thickness of $500 \mathrm{~nm}$ [114]. The measured system can be seen in Figure 7c,d shows that the bandgap energy Eg of $\mathrm{ZnO}$ thin film decreases with the temperature increase. After optimizing the light source $(47 \mathrm{~nm})$ and annealing $\mathrm{ZnO}$ film in air at $673 \mathrm{~K}$, the results show that the temperature sensor possessed a wide measurement range $(373-873 \mathrm{~K})$, a high resolution of $1{ }^{\circ} \mathrm{C}$ and a superior sensitivity of $0.06 \mathrm{~m}^{\circ} \mathrm{C}^{-1}$. Therefore, this temperature nanosensor is suitable to be applied in some more demanding environments. Another research, reported by C. H. Sui et al., presented an optical temperature sensor based on $\mathrm{ZnO}$ thin film which was only related to the wavelength shift of transmittance spectra. Further, it illustrated that a fiber optical sensor could work with a broad temperature measurement range of 10-1800 K, which shows the promising utilization potentiality of $\mathrm{ZnO}$ optical fiber temperature sensors [111].

\subsubsection{Discussions}

As discussed above, $\mathrm{ZnO}$ temperature nanosensors have been studied a lot and the device structure and performance improved significantly. ZnO plays an important role in temperature nanosensors, because its carrier concentration and energy gap are sensitive to the temperature, which affects the conduction characteristics. Due to the faster electron transportation of one-dimensional $\mathrm{ZnO}$ nanostructures, they are more suitable for the preparation of temperature sensors. However, in order to meet the higher aggregate demand of future applications, there are still some key technologies for $\mathrm{ZnO}$ temperature sensors to be broken through. For example, the temperature measurement range and stability can be further optimized by regulating the quality of $\mathrm{ZnO}$ nanomaterials; the integration of the temperature sensor can be enhanced by compressing the device structure, which is a great challenge to device fabrication technology. Further, the heat capacity and maximum temperature that can be sustained by the device should be increased by exploring the temperature transfer and compensation between $\mathrm{ZnO}$ and the remaining structures of the device. Therefore, the future research on $\mathrm{ZnO}$ temperature sensor still remains abundant and arduous.

\section{Conclusions and Prospects}

In this review, firstly, $\mathrm{ZnO}$ nanostructures and the main synthetic methods of $\mathrm{ZnO}$ materials were introduced. Then, the development of several types of nanosensors based on $\mathrm{ZnO}$ were reviewed intensively, including pressure sensors, gas sensors, photoelectric sensors, biosensors and temperature sensors. The sensing mechanism, recent research progress and challenge problems were described for each type of sensor, respectively. All the above $\mathrm{ZnO}$ nanosensors show excellent sensitivity, responsivity and stability, due to the superior piezoelectric properties, photoelectric properties, electronic transmission and the large surface area of $\mathrm{ZnO}$ nanostructures. Therefore, the $\mathrm{ZnO}$ nanosensors have attracted wide attention not only in scientific research but also in various application fields.

Although favorable sensing performance has been achieved for some $\mathrm{ZnO}$ nanosensors in recent years, many challenges for commercial applications still remain to be overcome. First, the high-quality and stable p-type $\mathrm{ZnO}$ materials have become the bottleneck 
for material synthesis, which restricts the development of $\mathrm{ZnO}$ nanosensors seriously. In addition, it is a key difficult problem to precisely control the morphology of $\mathrm{ZnO}$ nanostructures, which plays a vital role in nanosensors. Moreover, how to further improve the selectivity and response of $\mathrm{ZnO}$ nanosensors is still a research direction worth exploring. Finally, there are many obstacles in realizing $\mathrm{ZnO}$ nanosensors with high integration and multi-function, which is the inevitable trend of development for electronic devices in the future. At present, the majority of $\mathrm{ZnO}$ sensors are single-function and only a few works have realized multi-function sensors at the same time [115]. For example, Y. Wang et al. demonstrated a pressure and light difunctional sensor based on $\mathrm{ZnO}$ NW/Graphene [116]. However, the realization of multifunctional sensors not only needs to solve the problems of integration process, but also needs to overcome the technical challenges of signal recognition, transmission and mutual disturbance when multiple physical quantities are measured simultaneously. Therefore, the research of multifunctional $\mathrm{ZnO}$ sensors is an enormous challenge.

In view of the above problems, the future research on $\mathrm{ZnO}$ nanosensors may focus on the following aspects. The synthesis methods of P-type $\mathrm{ZnO}$ and $\mathrm{ZnO}$ complex need to be further improved to provide comprehensive $\mathrm{ZnO}$ nanomaterials with high quality, which is an important foundation for the development of $\mathrm{ZnO}$ nanosensors. How to achieve the precise control of the surface of the synthetic nanomaterials is a key step to promote the preparation process of $\mathrm{ZnO}$. The selectivity of $\mathrm{ZnO}$ sensors could be improved by introducing surface catalysts, modification with functional group and doping of $\mathrm{ZnO}$, which would enhance the reception rate of the target detection objects. Meanwhile, the response of $\mathrm{ZnO}$ sensors could be improved by further optimizing the quality of $\mathrm{ZnO}$ nanomaterials and device structure. Under the premise of ensuring the performance, the main approaches to promote sensors moving towards high integration and multi-function are simplifying the device structure, reducing the physical size and increasing the compatibility of $\mathrm{ZnO}$ and other materials. Therefore, great and collective efforts are essential to address these challenges and we believe that $\mathrm{ZnO}$ nanosensors possess enormous potential for future applications in various electronic systems and artificial intelligence.

Author Contributions: Conceptualization, M.Q., C.L., J.S., L.C., X.S. and Y.S.; formal analysis, M.Q., C.L., J.S., L.C., X.S. and Y.S.; investigation, M.Q., C.L., J.S. and L.C.; data curation, M.Q., C.L., J.S., L.C., X.S. and Y.S.; writing-original draft preparation, M.Q.; writing-review and editing, M.Q., C.L., J.S., L.C., X.S. and Y.S. All authors have read and agreed to the published version of the manuscript.

Funding: This research was funded by the Foundation of Jiangsu Provincial Department of Science and Technology, grant number BK20180966, the Foundation of Jiangxi Provincial Department of Science and Technology, grant number 20202BAB212001, the National Natural Science Foundation of China, grant number 22008029, and the Qing Lan Project of Jiangsu Province.

Institutional Review Board Statement: Not applicable.

Informed Consent Statement: Not applicable.

Data Availability Statement: Not applicable.

Acknowledgments: This work was supported by the Foundation of Jiangsu Provincial Department of Science and Technology (No. BK20180966), the Foundation of Jiangxi Provincial Department of Science and Technology (No. 20202BAB212001), the National Natural Science Foundation of China (No. 22008029) and the Qing Lan Project of Jiangsu Province.

Conflicts of Interest: The authors declare no conflict of interest. 


\section{References}

1. Srinivasan, P.; Mehtre, S. Zinc oxide nanoparticles from Coriandrum sativum as sensor for detection of n-butanol and nitric oxide gas. Mater. Today Proc. 2021. [CrossRef]

2. Verma, V.; Kala, D.; Gupta, S.; Kumar, H.; Kumar, D. Leptospira interrogans Outer Membrane Protein-Based Nanohybrid Sensor for the Diagnosis of Leptospirosis. Sensors 2021, 21, 2552. [CrossRef]

3. Li, L.; Lin, D.; Yang, F.; Xiao, Y.; Jiang, C. Gold Nanoparticle-Based Peroxyoxalate Chemiluminescence System for Highly Sensitive and Rapid Detection of Thiram Pesticides. ACS Appl. Nano Mater. 2021, 4, 3932-3939. [CrossRef]

4. Oezguer, U.; Alivov, Y.I.; Liu, C.; Teke, A.; Reshchikov, M.A.; Dogan, S.; Avrutin, V.; Cho, S.J.; Morkoc, H. A comprehensive review of ZnO materials and devices. J. Appl. Phys. 2005, 98, 1-11.

5. Miranda, E.; Milano, G.; Ricciardi, C. Compact Modeling of the I-V Characteristics of ZnO Nanowires Including Nonlinear Series Resistance Effects. IEEE Trans. Nanotechnol. 2020, 19, 297-300. [CrossRef]

6. Wu, Y.; Hasan, T.; Li, X.; Xu, P.; Wang, Y.; Shen, X.; Liu, X.; Yang, Q. High efficiency single Ag nanowire/p-GaN substrate Schottky junction-based ultraviolet light emitting diodes. Appl. Phys. Lett. 2015, 106, 051108. [CrossRef]

7. Que, M.; Zhou, R.; Wang, X.; Yuan, Z.; Hu, G.; Pan, C. Progress in piezo-phototronic effect modulated photovoltaics. J. Phys. Condens. Matter. 2016, 28, 433001. [CrossRef]

8. Wang, Y.; Zhu, L.; Du, C. Flexible Difunctional (Pressure and Light) Sensors Based on ZnO Nanowires/Graphene Heterostructures. Adv. Mater. Interfaces 2020, 7, 1901932. [CrossRef]

9. Wang, Y.; Gong, Y.; Yang, L.; Xiong, Z.; Lv, Z.; Xing, X.; Zhou, Y.; Zhang, B.; Su, C.; Liao, Q. MXene-ZnO Memristors: MXene-ZnO Memristor for Multimodal In-Sensor Computing. Adv. Funct. Mater. 2021, 31, 135. [CrossRef]

10. Li, J.; Jiang, M.; Xu, C.; Wang, Y.; Lin, Y.; Lu, J.; Shi, Z. Plasmon coupled Fabry-Perot lasing enhancement in graphene/ZnO hybrid microcavity. Sci. Rep. 2015, 5, 9263. [CrossRef]

11. Chen, X.; Wang, Q.; Wang, X.J.; Li, J.; Xu, G.B. Synthesis and performance of ZnO quantum dots water-based fluorescent ink for anti-counterfeiting applications. Sci. Rep. 2021, 11, 5841. [CrossRef] [PubMed]

12. Zhou Xiaofeng, J.T.; Zhang, J.; Wang, X.; Zhu, Z. Humidity sensor based on quartz tuning fork coated with sol-gel-derived nanocrystalline zinc oxide thin film. Sens. Actuators B Chem. 2007, 123, 299-305. [CrossRef]

13. Que, M.; Guo, W.; Zhang, X.; Li, X.; Hua, Q.; Dong, L.; Pan, C. Flexible quantum dot-sensitized solar cells employing CoS nanorod arrays/graphite paper as effective counter electrodes. J. Mater. Chem. A 2014, 2, 13661. [CrossRef]

14. An, J.; Qin, W.; Wen, X. A novel self-supported porous ZnO nanobelt arrays on Zn foils: Excellent binder-free anode materials for LIBs. Nanotechnology 2021, 32, 1431. [CrossRef]

15. Zhu, Y.W.; Zhang, H.Z.; Sun, X.C.; Feng, S.Q.; Xu, J.; Zhao, Q.; Xiang, B.; Wang, R.M.; Yu, D.P. Efficient field emission from ZnO nanoneedle arrays. Appl. Phys. Lett. 2003, 83, 144-146. [CrossRef]

16. Djurisic, A.B.; Hsu, Y.F.; Xi, Y.Y.; Ng, A.M.C.; Tam, K.H.; Chant, W.K. ZnO Nanorod Heterojunctions and LEDs. In Proceedings of the 2008 2nd IEEE International Nanoelectronics Conference, Shanghai, China, 24-27 March 2008; pp. 182-185.

17. Li, X.; Chen, M.; Yu, R.; Zhang, T.; Pan, C. Enhancing Light Emission of ZnO-Nanofilm/Si-Micropillar Heterostructure Arrays by Piezo-Phototronic Effect. Adv. Mater. 2015, 27, 30. [CrossRef]

18. Sun, H.; Luo, M.; Weng, W.; Cheng, K.; Du, P.; Shen, G.; Han, G. Room-temperature preparation of ZnO nanosheets grown on Si substrates by a seed-layer assisted solution route. Nanotechnology 2008, 19, 125603. [CrossRef]

19. Zhao, Y.; Liu, B.H.; Liu, N.; Yu, H.; Yang, Y.; Dong, X.T. Preparation and gas-sensitive properties of litchi shell-like NiO film modified porous $\mathrm{ZnO}$ composite by electrodeposition method. Sens. Actuators A Phys. 2021, 320, 112574. [CrossRef]

20. Savka, S.; Venhryn, Y.; Serednytski, A.; Popovych, D. Molecular dynamics simulation of adsorption processes on the surface of ZnO nanoclusters. Appl. Nanosci. 2021, 50, 1-6.

21. Yan, C.; Xue, D. Room temperature fabrication of hollow ZnS and ZnO architectures by a sacrificial template route. J. Phys. Chem. $B$ 2006, 110, 7102-7106. [CrossRef]

22. Wang, Z.L. ZnO nanowire and nanobelt platform for nanotechnology. Mater. Sci. Eng. R 2009, 64, 33-71. [CrossRef]

23. Zhu, R.; Zhang, W.; Li, C.; Yang, R. Uniform zinc oxide nanowire arrays grown on nonepitaxial surface with general orientation control. Nano Lett. 2013, 13, 5171-5176. [CrossRef]

24. Sheng, X.; Yong, D.; Wei, Y.; Hao, F.; Yue, S.; Sood, A.K.; Polla, D.L.; Zhong, L.W. Patterned growth of horizontal ZnO nanowire arrays. J. Am. Chem. Soc. 2009, 131, 6670-6671.

25. Xu, S.; Xu, C.; Liu, Y.; Hu, Y.; Yang, R.; Yang, Q.; Ryou, J.H.; Kim, H.J.; Lochner, Z.; Choi, S.; et al. Ordered nanowire array blue/near-UV light emitting diodes. Adv. Mater. 2010, 22, 4749-4753. [CrossRef] [PubMed]

26. Bao, R.; Wang, C.; Dong, L.; Yu, R.; Zhao, K.; Wang, Z.L.; Pan, C. Flexible and Controllable Piezo-Phototronic Pressure Mapping Sensor Matrix by ZnO NW/p-Polymer LED Array. Adv. Funct. Mater. 2015, 25, 2884-2891. [CrossRef]

27. Wang, Z.L. From nanogenerators to piezotronics-A decade-long study of ZnO nanostructures. MRS Bull. 2012, 37, 814-827. [CrossRef]

28. Sekiguchi, T.; Miyashita, S.; Obara, K.; Shishido, T.; Sakagami, N. Hydrothermal growth of ZnO single crystals and their optical characterization. J. Cryst. Growth 2000, 214, 72-76. [CrossRef]

29. Jaiswal, N.; Pandey, C.M.; Solanki, S.; Tiwari, I.; Malhotra, B.D. An impedimetric biosensor based on electrophoretically assembled $\mathrm{ZnO}$ nanorods and carboxylated graphene nanoflakes on anindium tin oxide electrode fordetection of the DNA of Escherichia coli O157:H7. Microchim. Acta 2020, 187, 1. [CrossRef] [PubMed] 
30. Shin, J.; Cho, S. Effect of annealing temperature on properties of yttrium-doped ZnO thin films grown by radio-frequency magnetron sputtering. Appl. Phys. A 2019, 125, 809. [CrossRef]

31. Nakahara, R.; Sakai, M.; Kimura, T.; Yamamoto, M.; Kouno, T. Lasing action of ZnO nanowires grown by mist chemical vapor deposition using thin Au layer on c-plane sapphire substrate. Jpn. J. Appl. Phys. 2021, 60, 1374. [CrossRef]

32. Zheng, J.X.; Luo, Y.Q.; Wen, X.B.; Zhang, Q.L.; Song, Y.; Zhou, J.D.; Jiang, N.Q.; Liu, L.L.; Huang, F.; Xie, Z.Q. Induced crystallization of sol-gel-derived zinc oxide for efficient non-fullerene polymer solar cells. J. Mater. Chem. A 2021, 9, 325. [CrossRef]

33. Fei, X.; Jiang, D.; Wang, N.; Zhao, H.; Xing, M.; Li, H. Study on Ultraviolet Photodetector modified by Au Nanoparticles on ZnO Nanowires. J. Phys. Conf. Ser. 2021, 1907, 012044. [CrossRef]

34. Haga, H.; Jinnai, M.; Ogawa, S.; Kuroda, T.; Kato, Y.; Ishizaki, H. Rapid fabrication of ZnO film by electrochemical deposition method from aqueous solution. Electr. Eng. Jpn. 2021, 140, 357-363.

35. Barman, B.; Swami, S.K.; Dutta, V. Fabrication of highly conducting ZnO/Ag/ZnO and AZO/Ag/AZO transparent conducting oxide layers using RF magnetron sputtering at room temperature. Mat. Sci. Semicon. Proc. 2021, 129, 105801. [CrossRef]

36. Ariza, R.; Dael, M.; Sotillo, B.; Urbieta, A.; Solis, J.; Fernandez, P. Vapor-solid growth ZnO: $\mathrm{ZrO}_{2}$ micro and nanocomposites. J. Alloy Compd. 2021, 877, 160219. [CrossRef]

37. Narin, P.; Kutlu-Narin, E.; Lisesivdin, S.B. Growth dynamics of mist-CVD grown ZnO nanoplatelets. Phys. B Condens. Matter 2021, 614, 413028. [CrossRef]

38. Yuan, H.; Aljneibi, S.; Yuan, J.; Wang, Y.; Liu, H.; Fang, J.; Tang, C.; Yan, X.; Cai, H.; Gu, Y. Biosensors: ZnO Nanosheets Abundant in Oxygen Vacancies Derived from Metal-Organic Frameworks for ppb-Level Gas Sensing. Adv. Mater. 2019, $31,1970076$.

39. Yao, M.S.; Tang, W.X.; Wang, G.E.; Nath, B.; Xu, G. MOF Thin Film-Coated Metal Oxide Nanowire Array: Significantly Improved Chemiresistor Sensor Performance. Adv. Mater. 2016, 28, 5229-5234. [CrossRef] [PubMed]

40. Venhryn, Y.I.; Pawluk, V.S.; Serednytski, A.S.; Popovych, D.I. Photoluminescence in gas of (Ca) Mg-doped ZnO nanopowders. Appl. Nanosci. 2021, 1-6. [CrossRef]

41. Zhou, X.; Wang, S.; Zhang, C.; Lin, Y.; Lv, J.; Hu, S.; Zhang, S.; Li, M. Colorimetric determination of amyloid- $\beta$ peptide using MOF-derived nanozyme based on porous ZnO-Co 3 O 4 nanocages. Microchim. Acta 2021, 188, 1-10. [CrossRef] [PubMed]

42. Jali, M.H.; Rahim, H.R.A.; Johari, M.A.M.; Yusof, H.H.M.; Ahmad, A.; Thokchom, S.; Dimyati, K.; Harun, S.W. Humidity sensing using microfiber-ZnO nanorods coated glass structure. Optik 2021, 238, 166715. [CrossRef]

43. Yang, Q.; Wu, Y.; Liu, Y.; Pan, C.; Wang, Z.L. Features of the piezo-phototronic effect on optoelectronic devices based on wurtzite semiconductor nanowires. Phys. Chem. Chem. Phys. 2014, 16, 2790-2800. [CrossRef] [PubMed]

44. Li, L.; Zhang, Y.; Wang, R.; Sun, J.; Dai, Y. Ferroelectricity-induced performance enhancement of V-doped ZnO/Si photodetector by direct energy band modulation. Nano Energy 2019, 65, 104046. [CrossRef]

45. Anjana, R.; Subha, P.P.; Markose, K.K.; Jayaraj, M.K. Enhanced green upconversion luminescence in $\mathrm{ZnO}^{2} \mathrm{Er}^{3+}, \mathrm{Yb}^{3+} \mathrm{on} \mathrm{Mo}^{6+}$ co-doping for temperature sensor application. Methods Appl. Fluoresc. 2017, 6, 015005. [CrossRef]

46. Cao, L.; Kiely, J.; Piano, M.; Luxton, R. Nanoparticle-based 3D membrane for impedimetric biosensor applications. Bioelectrochemistry 2020, 136, 107593. [CrossRef]

47. Aykac, A.; Tunc, I.D.; Gunes, F.; Erol, M.; Sen, M. Sensitive PH measurement using EGFET PH-microsensor based on ZnO nanowire functionalized carbon-fibers. Nanotechnology 2021, 32, 4621. [CrossRef]

48. Hassan, K.; Hossain, R.; Farzana, R.; Sahajwalla, V. Microrecycled zinc oxide nanoparticles (ZnO NP) recovered from spent Zn-C batteries for VOC detection using ZnO sensor. Anal. Chim. Acta 2021, 1165, 338563. [CrossRef]

49. Bao, R.; Hu, Y.; Yang, Q.; Pan, C. Piezo-phototronic effect on optoelectronic nanodevices. MRS Bull. 2018, 43, 952-958. [CrossRef]

50. Yang, X.; Hu, G.; Gao, G.; Chen, X.; Sun, J.; Wan, B.; Zhang, Q.; Qin, S.; Zhang, W.; Pan, C. Coupled Ion-Gel Channel-Width Gating and Piezotronic Interface Gating in ZnO Nanowire Devices. Adv. Funct. Mater. 2019, 29, 1807837. [CrossRef]

51. Min, Y.; Lai, Y.H.; Zhang, C.L.; Cheng, H.Y.; Chu, Y.H. Giant Resistivity Change of Transparent ZnO/Muscovite Heteroepitaxy. ACS Appl. Mater. Interfaces 2020, 12, 21818-21826.

52. Oh, H.; Dayeh, S.A. Physics-Based Device Models and Progress Review for Active Piezoelectric Semiconductor Devices. Sensors 2020, 20, 3872. [CrossRef]

53. Vishniakou, S.; Chen, R.; Ro, Y.G.; Brennan, C.J.; Levy, C.; Yu, E.T.; Dayeh, S.A. Improved Performance of Zinc Oxide Thin Film Transistor Pressure Sensors and a Demonstration of a Commercial Chip Compatibility with the New Force Sensing Technology. Adv. Mater. Technol. 2018, 3, 1700279. [CrossRef]

54. Wen, X.; Wu, W.; Ding, Y.; Wang, Z.L. Piezotronic effect in flexible thin-film based devices. Adv. Mater. 2013, 25, 3371-3379. [CrossRef]

55. Pradel, K.C.; Wu, W.; Zhou, Y.; Wen, X.; Ding, Y.; Wang, Z.L. Piezotronic Effect in Solution-Grown p-Type ZnO Nanowires and Films. Nano Lett. 2013, 13, 2647. [CrossRef]

56. Huo, Z.; Wang, X.; Zhang, Y.; Bensong, W.; Wu, W.; Xi, J.; Yang, Z.; Hu, G.; Li, X.; Pan, C. High-performance Sb-doped p-ZnO NW films for self-powered piezoelectric strain sensors. Nano Energy 2020, 73, 104744. [CrossRef]

57. Tan, Y.; Yang, K.; Wang, B.; Li, H.; Wang, L.; Wang, C. High-performance textile piezoelectric pressure sensor with novel structural hierarchy based on $\mathrm{ZnO}$ nanorods array for wearable application. Nano Res. 2021. [CrossRef]

58. Pan, C.; Dong, L.; Zhu, G.; Niu, S.; Yu, R.; Yang, Q.; Liu, Y.; Wang, Z.L. High-resolution electroluminescent imaging of pressure distribution using a piezoelectric nanowire LED array. Nat. Photonics 2013, 7, 752-758. [CrossRef] 
59. Peng, Y.; Que, M.; Lee, H.E.; Bao, R.; Wang, X.; Lu, J.; Yuan, Z.; Li, X.; Tao, J.; Sun, J.; et al. Achieving high-resolution pressure mapping via flexible GaN/ZnO nanowire LEDs array by piezo-phototronic effect. Nano Energy 2019, 58, 633-640. [CrossRef]

60. Wang, F.; Jiang, J.; Liu, Q.; Zhang, Y.; Sang, Y. Piezopotential gated two-dimensional InSe field-effect transistor for designing a pressure sensor based on piezotronic effect. Nano Energy 2020, 70, 104457. [CrossRef]

61. Amano, J. Piezoelectric Cantilever Pressure Sensor Array. U.S. Patent 7,032,454, 25 April 2005.

62. Wu, W.; Wen, X.; Wang, Z.L. Taxel-Addressable Matrix of Vertical-Nanowire Piezotronic Transistors for Active and Adaptive Tactile Imaging. Science 2013, 340, 952-957. [CrossRef] [PubMed]

63. Dhanaselvam, P.S.; Kumar, D.S.; Ramakrishnan, V.N.; Ramkumar, K.; Balamurugan, N.B. Pressure Sensors Using Si/ZnO Heterojunction Diode. Silicon 2021, 1-7. [CrossRef]

64. Liu, M.; Liu, Y.; Zhou, L. Novel Flexible PVDF-TrFE and PVDF-TrFE/ZnO Pressure Sensor: Fabrication, Characterization and Investigation. Micromachines 2021, 12, 602. [CrossRef]

65. Zhao, S.; Shen, Y.; Xia, Y.; Pan, A.; Li, Z.; Carraro, C.; Maboudian, R. Synthesis and gas sensing properties of NiO/ZnO heterostructured nanowires. J. Alloy Compd. 2021, 877, 160189. [CrossRef]

66. Li, H.Y.; Zhao, S.N.; Zang, S.Q.; Li, J. Functional metal-organic frameworks as effective sensors of gases and volatile compounds. Chem. Soc. Rev. 2020, 49, 17. [CrossRef]

67. Tian, H.; Fan, H.; Li, M.; Ma, L. Zeolitic Imidazolate Framework Coated ZnO Nanorods as Molecular Sieving to Improve Selectivity of Formaldehyde Gas Sensor. ACS Sens. 2015, 1, 243-250. [CrossRef]

68. Kaiser, A.; Ceja, E.T.; Liu, Y.; Huber, F.; Müller, R.; Herr, U.; Thonke, K. H2S sensing for breath analysis with Au functionalized ZnO nanowires. Nanotechnology 2021, 32, 205505. [CrossRef]

69. Zhang, Z.; Chen, X.; Kang, J.; Yu, Z.; Huang, W. The active sites of Cu-ZnO catalysts for water gas shift and CO hydrogenation reactions. Nat. Commun. 2021, 12, 4331. [CrossRef] [PubMed]

70. Dineshkumar, M. Fabrication and Analysis of Energy Efficient Low-Cost Wireless Gas Sensor Based on ZnO Thin Films. J. Nanosci. Nanotechnol. 2021, 21, 4. [CrossRef]

71. Ramola, R.C.; Negi, S.; Rawat, M.S.; Singh, R.C.; Singh, F. Annealing Effects on Gas Sensing Response of Ga-Doped ZnO Thin Films. ACS Omega 2021, 6, 11660-11668. [CrossRef] [PubMed]

72. Meng, J.; Li, H.; Zhao, L.; Lu, J.; Pan, C.F.; Li, Z. Triboelectric Nanogenerator Enhanced Schottky Nanowire Sensor for Highly Sensitive Ethanol Detection. Nano Lett. 2020, 20, 4968-4974. [CrossRef] [PubMed]

73. Bhat, K.S.; Ahmad, R.; Mahmoudi, T.; Hahn, Y.-B. High performance chemical sensor with field-effect transistors array for selective detection of multiple ions. Chem. Eng. J. 2021, 417, 128064. [CrossRef]

74. Sahibzada, M.; Metcalfe, I.S.; Chadwick, D. Methanol Synthesis from CO/CO2/H2over Cu/ZnO/Al2O3at Differential and Finite Conversions. J. Catal. 1998, 174, 111-118. [CrossRef]

75. Mridha, S.; Basak, D. Investigation of a $\mathrm{p}-\mathrm{CuO} / \mathrm{n}-\mathrm{ZnO}$ thin film heterojunction for $\mathrm{H} 2$ gas-sensor applications. Semicond. Sci. Technol. 2006, 21, 928. [CrossRef]

76. Chang, S.; Hsueh, T.; Chen, I.; Hsieh, S.; Chang, S.; Hsu, C.; Lin, Y.; Huang, B. Highly Sensitive ZnO Nanowire Acetone Vapor Sensor With Au Adsorption. IEEE Trans. Nanotechnol. 2008, 7, 754-759. [CrossRef]

77. Zhang, Y.-H.; Liu, C.-Y.; Jiu, B.-B.; Liu, Y.; Gong, F.-L. Facile synthesis of Pd-decorated ZnO nanoparticles for acetone sensors with enhanced performance. Res. Chem. Intermed. 2018, 44, 1569-1578. [CrossRef]

78. Td, A.; Ga, A.; Aod, B.; Ga, C.; Mm, D.; Mt, D.; Ps, A.; Nnn, B. Effect of Pd-decoration on the sensing properties of ZnO nanostructures-ScienceDirect. Thin Solid Films 2019, 693, 137693.

79. Td, A.; Ga, A.; Aod, B.; Nnn, B. The effect of light irradiation on the gas-sensing properties of nanocomposites based on $\mathrm{ZnO}$ and Ag nanoparticles-ScienceDirect. Appl. Surf. Sci. 2019, 505, 144625.

80. Wang, H.; Bai, J.; Dai, M.; Liu, K.; Lu, G. Visible light activated excellent NO2 sensing based on 2D/2D ZnO/g-C3N4 heterojunction composites. Sens. Actuators B Chem. 2019, 304, 127287. [CrossRef]

81. Cao, F. Preparation of Zno Nanostructures and Their Applications in Gas Sensors. Master's Thesis, Tianjin University of Technology, Tianjin, China, 2018. (In Chinese).

82. Huerta, A.T.; Perez-Sanchez, G.F.; Chavez, F.; Zaca-Moran, P.; Cortes-Salinas, D. ZnO Nanowires Synthesized by CSS and their Application as a Hydrogen Gas Sensor. In Proceedings of the 2013 10th International Conference on Electrical Engineering, Computing Science and Automatic Control (CCE), Mexico City, Mexico, 30 September-4 October 2013; pp. $488-492$.

83. Raj, I.L.P.; Gobalakrishnan, S.; Praseetha, P.K.; Chidhambaram, N.; Saravanakumar, S.; Ganesh, V.; AlFaify, S.; Algarni, H.; Yahia, I.S. Improved ammonia vapor sensing properties of Al-doped ZnO nanoparticles prepared by sol-gel process. Phys. Scr. 2021, 96, 085802.

84. Zhang, L.; Wan, P.; Xu, T.; Kan, C.; Jiang, M. Flexible ultraviolet photodetector based on single ZnO microwire/polyaniline heterojunctions. Opt. Express 2021, 29, 19202-19213. [CrossRef]

85. Kwon, J.B.; Kim, S.W.; Lee, J.S.; Park, C.E.; Kim, O.S.; Xu, B.; Bae, J.H.; Kang, S.W. Uncooled Short-Wave Infrared Sensor Based on PbS Quantum Dots Using ZnO NPs. Nanomaterials 2019, 9, 926. [CrossRef]

86. Soci, C.; Zhang, A.; Xiang, B.; Dayeh, S.A.; Aplin, D.; Park, J.; Bao, X.Y.; Lo, Y.H.; Wang, D. ZnO nanowire UV photodetectors with high internal gain. Nano Lett. 2007, 7, 1003. [CrossRef]

87. Cavas, M. Improving Electrical and Optical Properties of ZnO/p-Si Optical Sensor. Iran. J. Sci. Technol. Trans. A Sci. 2020, 44, 289-297. [CrossRef] 
88. Jeon, M.B.; Kwak, Y.H.; Ju, B.K.; Kim, K. Ultraviolet sensor with fast response characteristics based on an AgNW/ZnO bi-layer. Sens. Actuators A Phys. 2020, 311, 112044. [CrossRef]

89. Han, X.; Du, W.; Yu, R.; Pan, C.; Wang, Z.L. Piezo-Phototronic Enhanced UV Sensing Based on a Nanowire Photodetector Array. Adv. Mater. 2015, 27, 7963-7969. [CrossRef]

90. Li, H.; Zhao, L.; Meng, J.; Pan, C.; Zhang, Y.; Zhang, Y.; Liu, Z.; Zou, Y.; Fan, Y.; Wang, Z.L.; et al. Triboelectric-polarizationenhanced high sensitive ZnO UV sensor. Nano Today 2020, 33, 100873. [CrossRef]

91. Wang, Z.Y.; Qiu, X.T.; Chen, S.J.; Pang, W.; Zhang, H.; Shi, J.; Yu, H.Y. ZnO based film bulk acoustic resonator as infrared sensor. Thin Solid Films 2011, 519, 6144-6147. [CrossRef]

92. Feng, Y.; Chen, J.; Liu, C.; Wang, T.; Shen, T. A first-principle study on photoelectric characteristics of Ce-doped ZnO. Ferroelectrics 2021, 573, 214-223. [CrossRef]

93. Xie, Y.; Li, H.; Zhang, D.; Wang, Q.; Zhang, L. High performance blue light detector based on ZnO nanowire arrays. Appl. Opt. 2019, 58, 1242-1245. [CrossRef] [PubMed]

94. Zhao, Y.F.; Zhang, M.; Yang, L.Y.; Zhang, J.; Wang, Z.J. Ultraviolet photodetector based on NaTaO3/ZnO composite with enhanced photoelectric performance. Optoelectron. Lett. 2021, 17, 75-79. [CrossRef]

95. Wang, M.; Zhou, Y.; Zhang, Y.; Kim, E.J.; Hahn, S.H.; Seong, S.G. Near-infrared photoluminescence from ZnO. Appl. Phys. Lett. 2012, 100, 041301. [CrossRef]

96. Fang, F.; Kennedy, J.V.; Futter, R.J.; Leveneur, J. ZnO Nanostructures Synthesized by Arc Discharge for Optical Coating and Sensor Applications. In Proceedings of the 2013 Seventh International Conference on Sensing Technology (ICST), Wellington, New Zealand, 3-5 December 2013; pp. 869-873.

97. Zhang, F.; Niu, S.; Guo, W.; Zhu, G.; Liu, Y.; Zhang, X.; Wang, Z.L. Piezo-phototronic effect enhanced visible/UV photodetector of a carbon-fiber/ZnO-CdS double-shell microwire. ACS Nano 2013, 7, 4537-4544. [CrossRef] [PubMed]

98. Gurylev, V.; Perng, T.P. Defect engineering of ZnO: Review on oxygen and zinc vacancies. J. Eur. Ceram Soc. 2021, 41, 4977-4996. [CrossRef]

99. Abdulrahman, A.F.; Abd-Alghafour, N.M.; Ahmed, S.M. Optimization and characterization of SILAR synthesized ZnO nanorods for UV photodetector sensor. Sens. Actuators A Phys. 2021, 323, 112656. [CrossRef]

100. Alam, M.M.; Rahman, M.M.; Uddin, M.T.; Asiri, A.M.; Islam, M.A. Development of l-glutamic acid biosensor with ternary $\mathrm{ZnO} / \mathrm{NiO} / \mathrm{Al} 2 \mathrm{O} 3$ nanoparticles. J. Lumin. 2020, 227, 117528. [CrossRef]

101. Kg, A.; Adbc, D.; Uh, A.; Ma, E.; Ab, F.; Kmb, G.; Sfa, H.; Mk, H.; Ehr, I. Fabrication and characterizations of Al nanoparticles doped $\mathrm{ZnO}$ nanostructures-based integrated electrochemical biosensor. J. Mater. Res. Technol. 2020, 9, 857-867.

102. Feng, X.; Feng, L.; Jin, M.; Zhai, J.; Jiang, L.; Zhu, D. Reversible Super-hydrophobicity to Super-hydrophilicity Transition of Aligned ZnO Nanorod Films. J. Am. Chem. Soc. 2004, 126, 62-63. [CrossRef] [PubMed]

103. Kasiviswanathan, U.; Kumar, C.; Poddar, S.; Jit, S.; Mahto, S.K. Extended Large Area Si/ZnO Heterojunction Biosensor for Assessing Dynamic Behaviour of Primary Cortical Neuronal Cells. IEEE Sens. J. 2021, 21, 14619-14626. [CrossRef]

104. Kamaci, M.; Kamaci, M. Selective and Sensitive ZnO Quantum Dots Based Fluorescent Biosensor for Detection of Cysteine. J. Fluoresc. 2021, 31, 401-414. [CrossRef]

105. Zhao, L.; Li, H.; Meng, J.; Wang, A.C.; Li, Z. Reversible Conversion between Schottky and Ohmic Contacts for Highly Sensitive, Multifunctional Biosensors. Adv. Funct. Mater. 2020, 30, 1907999. [CrossRef]

106. Zhao, M.G.; Shang, J.H.; Qu, H.Y.; Gao, R.J.; Li, H.; Chen, S.G. Fabrication of the Ni/ZnO/BiOI foam for the improved electrochemical biosensing performance to glucose. Anal. Chim. Acta 2020, 1095, 93-98. [CrossRef] [PubMed]

107. Kim, H.M.; Park, J.H.; Lee, S.K. Fiber optic sensor based on ZnO nanowires decorated by Au nanoparticles for improved plasmonic biosensor. Sci. Rep. 2019, 9, 15605. [CrossRef]

108. Pal, S.; Prajapati, Y.K.; Saini, J.P. Influence of graphene's chemical potential on SPR biosensor using ZnO for DNA hybridization. Opt. Rev. 2020, 27, 57-64. [CrossRef]

109. Dong, F. Electrochemical non-enzymatic biosensor for tyramine detection in food based on silver-substituted ZnO nano-flower modified glassy carbon electrode. Int. J. Electrochem. Sci. 2021, 16, 210234. [CrossRef]

110. Swaminathan, N.; Sharma, N.; Nerthigan, Y.; Wu, H.F. Self-assembled Diphenylalanine-Zinc Oxide hybrid nanostructures as a highly selective luminescent biosensor for Trypsin detection. Appl. Surf. Sci. 2021, 149600. [CrossRef]

111. Chenghua, S.; Juan, X.; Helin, W.; Tianning, X.; Bo, Y.; Yuling, L. Optical temperature sensor based on ZnO thin film's temperaturedependent optical properties. Rev. Sci. Instrum. 2011, 82, 498. [CrossRef] [PubMed]

112. Fabitha, K.; Rao, M. Biocompatible miniature temperature sensor based on whispering gallery modes of Sm $3+$ activated $\mathrm{ZnO}$ optical micro-resonators. Appl. Phys. Lett. 2021, 118, 163104. [CrossRef]

113. Xue, F.; Zhang, L.; Tang, W.; Zhang, C.; Du, W.; Wang, Z.L. Piezotronic Effect on ZnO Nanowire Film Based Temperature Sensor. ACS Appl. Mater. Interfaces 2014, 6, 5955-5961. [CrossRef]

114. Wang, H.L.; Yang, A.J.; Ling, T. Wide measurement-range fiber-optic temperature sensor based on ZnO thin film. Opt. Lasers Eng. 2014, 60, 49-53. [CrossRef]

115. Hui, G.H. A Novel Temperature Sensor Based on Gold Interdigital Electrodes and Nano ZnO Particles. Appl. Mech. Mater. 2010, 20-23, 1495-1498. [CrossRef] 
116. Zhou, J.; Zheng, J.; Shi, X.; Chen, Z.; Wu, J.; Xiong, S.; Luo, J.; Dong, S.; Jin, H.; Duan, H. Graphene-Based Fully Transparent Thin Film Surface Acoustic Wave Devices for Sensing and Lab-on-Chip Applications. J. Electrochem. Soc. 2019, 166, B432-B440. [CrossRef]

117. Hasan, S.A.; Gibson, D.; Song, S.; Qiang, W.; Fu, Y.Q. ZnO Thin Film Based Flexible Temperature Sensor. In Proceedings of the 2017 IEEE Sensors, Glasgow, UK, 29 October-1 November 2017; IEEE: Piscataway, NJ, USA, 2017.

118. Yamamoto, H.; Saiga, N.; Nishimori, K. Temperature Sensor Around $0{ }^{\circ} \mathrm{C}$ Using Surface Acoustic Wave Filter on ZnO/LiNbO3. IEEJ Trans. Sens. Micromach. 2003, 122, 285286. 